Investigaciones Fenomenológicas, n. 8, 2011, 97-149.

e-ISSN: $1885-1088$

\title{
LA CUESTIÓn del SUJeto EN LA fENOMENOLOgía de HuSSERL
}

\author{
Eduardo Álvarez \\ Universidad Autónoma de Madrid, España \\ eduardo.alvarez@uam.es
}

\begin{abstract}
Resumen: Se trata de examinar el significado -o los significados- del concepto del sujeto del que se sirve Husserl en los diversos niveles y perspectivas en que aparece en su obra, para hacer ver el sentido último que esta noción central alcanza a tener en la fenomenología, así como su función en el desarrollo de los conceptos principales de esta filosofía. El enfoque crítico que se adopta para abordar esta cuestión se sitúa en la posición de Husserl para apuntar, a partir de ahí, hacia una posición dialéctica.
\end{abstract}

Palabras clave: Husserl, fenomenología, sujeto, ego trascendental, intencionalidad, constitución.

\begin{abstract}
The aim is to examine the meaning -or meanings - of the concept of subject just as it appears on the different levels and perspectives in Husserl's work in order to see the utmost sense that this basic notion reaches in phenomenology as well as its function in the development of the main concepts of this philosophy. The critical approach assumed in this discussion places itself in Husserl's position to point out from there towards a dialectical position.
\end{abstract}

Keywords: Husserl, phenomenology, subject, transcendental ego, intentionality, constitution.

\section{LA CRISIS DE LA RAZÓN}

Y LA RECUPERACIÓN NEOCARTESIANA DEL ENFOQUE GNOSEOLÓGICO

Respecto del problema del sujeto, el pensamiento de Husserl significa un cambio de orientación en relación con el que se venía desarrollando de forma dominante en la segunda mitad del siglo XIX. El idealismo alemán había conducido el centro de interés filosófico más allá del enfoque gnoseológico característico de la reflexión moderna hasta hacer de la llamada "Teoría del conocimiento" un capítulo de la metafísica: el conocimiento mismo es interpretado por Hegel como un proceso que no cabe ya distinguir del proceso mismo por el que lo real se constituye como tal, de tal manera que la teoría del conocimiento es reinterpretada como ontología. Por su parte, la reacción antiespeculativa del 
positivismo y del materialismo decimonónicos, así como el descentramiento de la cuestión del conocimiento por parte de la Lebensphilosophie, no suponen una restauración del sujeto moderno, sino muy al contrario una crítica de ese viejo paradigma, tanto en sus formulaciones iniciales como en su reinterpretación posterior llevada a cabo por el idealismo alemán. Pues bien, en ese contexto histórico, el pensamiento de Husserl significa el proyecto renovado de fundar la filosofía en el ego cogito, repitiendo así a su manera el gesto cartesiano en busca de un nuevo comienzo radical que salga al paso de la profunda crisis intelectual de su tiempo.

Al igual que antes de él Comte y después Ortega, el diagnóstico de Husserl sobre su tiempo adopta la forma de la denuncia de una crisis intelectual, crisis en cuanto a la falta de fundamento, crisis de la ciencia, que a su vez juzga como "expresión de la crisis vital radical de la humanidad europea"1:

Se trata de una crisis que no ataca la especialización científica en sus éxitos teóricos y prácticos y que, sin embargo, quebranta a fondo su entero sentido de verdad [...] Porque la fundación originaria de la nueva filosofía coincide con la fundación originaria de la humanidad europea moderna [...] La crisis de la filosofía significa, pues, en orden a ello la crisis de todas las ciencias modernas en cuanto miembros de la universalidad filosófica, una crisis primero latente, pero luego cada vez más manifiesta, de la humanidad europea incluso en lo relativo al sentido global de su vida cultural, a su "existencia" toda. ${ }^{2}$

Y esa crisis, primariamente intelectual, pero que afecta globalmente a "la existencia toda", se refiere a la falta de fundamento en cuanto a la razón última que confiere sentido a nuestra experiencia. Por eso la respuesta ha de hallarse en el orden intelectual y en relación con esa búsqueda de carácter último: en la filosofía, por lo tanto, interpretada como ciencia estricta y ciencia de responsabilidad absoluta, y como autorreflexión de la humanidad ${ }^{3}$. Pues, según Husserl: "La filosofía, la ciencia, no sería, pues, sino el movimiento histórico de la reve-

\footnotetext{
${ }^{1}$ Edmund Husserl, Die Krisis der europäischen Wissenschaften und die transzendentale Phänomenologie, Husserliana, Hua VI, Den Haag, Martinus Nijhoff, 1962. Las citas están tomadas de la versión en español: La crisis de las ciencias europeas y la fenomenología transcendental, Barcelona, Crítica, 1991, cap. I, pp. 3ss. Traducción de Jacobo Muñoz y Salvador Mas. En adelante, citaremos como La crisis.

${ }^{2}$ Ibidem, cap. I, § 5, pp. 12s.

${ }^{3}$ Edmund Husserl, "Philosophie als strenge Wissenschaft", Logos (1911). Nos atenemos a una de las versiones en español de esta conferencia: La filosofía como ciencia estricta, Buenos Aires, Nova, 1981. Traducción de Elsa Tabernig. Esta publicación incluye, entre otros estudios de Husserl, la conferencia de este mismo título, así como otro que se incluyó luego en La crisis, como epílogo, § 73, con el título "La filosofía como autorreflexión de la humanidad, como autorrealización de la razón".
} 
lación de la razón universal, connatural -innata- a la humanidad en cuanto tal ${ }^{4}$.

Esa crisis es la que se manifiesta en el psicologismo de su tiempo, cuya crítica por parte de Husserl -que es el motivo fundamental de las Investigaciones lógicas - trata de poner de manifiesto que la racionalidad que puede fundar la ciencia y, más allá, una forma de vida acorde con la exigencia de la verdadera humanidad del hombre, ha de sostenerse y justificarse por sí misma, y eso significa hacerla independiente del nivel de los hechos: el sujeto racional no ha de ser comprendido en términos psicológicos, porque ello supondría reducirlo a un sujeto meramente fáctico, que es incapaz por naturaleza - según Husserlde dar cuenta de la aspiración a lo universal que alienta tanto en la ciencia como en los afanes de la razón práctica. Desde las Investigaciones lógicas -que plantean la crítica al psicologismo con relación a la lógica y la matemáticahasta La crisis de las ciencias europeas y la fenomenología trascendental -que renueva aquella crítica, referida ahora a las ciencias, cuya crisis de fundamento pondría de manifiesto la crisis del proyecto racional que define a la humanidad como tal $^{5}$, todo el proyecto de Husserl se puede interpretar como una filosofía del sujeto: de un sujeto cuya realidad como parte objetiva del mundo se trata de hacer compatible con su comprensión como sujeto racional que en cierto modo se adelanta a ese mismo mundo en la experiencia que tiene de él. En esta difícil tensión se constituye lo esencial de su pensamiento. La fenomenología es, en cualquier caso, un proyecto filosófico de recuperación del sujeto racional $^{6}$, proyecto que reacciona en contra de lo que Husserl interpreta como una crisis de la racionalidad con un alcance que marca la cultura de su tiempo, y que se elabora a partir de la tradición del idealismo moderno, sobre todo en la estela de Descartes y Kant.

Pues bien, el camino para la superación de esa crisis, interpretada en los términos de un idealismo intelectualista y cuyo alcance afectaría a todos los órdenes de la vida humana - pues en definitiva es la crisis de la racionalidad, que es la característica del hombre- conduce a Husserl a buscar en el ego cogito el comienzo fundador de una ciencia de evidencias apodícticas entre las

\footnotetext{
${ }^{4}$ La crisis, cap. I, § 6, p. 16.

${ }^{5}$ Vid. a este respecto el libro de Javier San Martín La fenomenología de Husserl como utopía de la razón, Barcelona, Anthropos, 1987. Aunque el libro en su conjunto insiste en este aspecto, recogido en su título, a ello se refiere en particular en las pp. 36-43.

${ }^{6}$ Vid. ibidem, p. 135
} 
que no cabe ninguna presunción como las que caracterizan a la actitud natural. La evidencia se convierte para él -como para Descartes- en el principio metódico normativo que confiere seguridad en el conoci-miento ${ }^{7}$. En este sentido, Husserl reconoce el acierto del método cartesiano de la duda, que cuestiona el ser del mundo, y realiza el giro que conduce a la subjetividad trascendental: "la vuelta hacia el ego cogito en cuanto base apodícticamente cierta y última de todo juicio, sobre la cual ha de fundamentarse toda filosofía radical" ${ }^{8}$.

Esta vuelta al sujeto por parte de Husserl parece obedecer, por lo tanto, al mismo proyecto que tres siglos antes guiara el esfuerzo cartesiano por encontrar una base indubitable para el conocimiento. Sin embargo, enseguida se hace claro que el camino de Husserl sigue otros derroteros, y ello afecta a diversos aspectos: tanto al método empleado para alcanzar ese principio fundamental buscado (la "epoché" y la "reducción" en lugar del método de la duda), como al rendimiento que se deriva del principio descubierto (todo el campo de la descripción y análisis de la experiencia fenomenológica), como finalmente, y sobre todo, al significado que se asigna a ese descubrimiento fundamental del ego puro.

Empezando por lo último (de los otros aspectos mencionados me ocuparé más adelante), Husserl explica que el error de Descartes consiste en que, estando ante el más grande de todos los descubrimientos - la subjetividad trascendental-, no supo interpretar correctamente el sentido de ese yo originario, traicionando de hecho su posición de principio, en cuanto convierte al ego en substantia cogitans, es decir, en una realidad en el sentido de cosa (res), en "la humana y separada mens sive animus ${ }^{9}$, como si se tratara de salvar una parcela del mundo cuya realidad precisamente ha sido puesta en cuestión. De tal modo que Descartes no traspasa el pórtico que lleva a la auténtica filosofía trascendental. Pues no se trata aquí del hombre que se encuentra en la experiencia natural de sí mismo, ni de la conciencia psicológica de sí, ni tampoco del alma. No se trata de ninguna forma de apercepción natural, que en todo caso

\footnotetext{
${ }^{7}$ Edmund Husserl, Cartesianische Meditationen, Hua I, Den Haag, Martinus Nijhoff, 1950. Citaremos los textos en su versión en español: Meditaciones cartesianas, Madrid, Tecnos, 1986, Meditación primera, $\S \S 5-6$, y Meditación tercera, $\S \S 24$ y 27-8. Traducción de Mario A. Presas.

${ }^{8}$ Ibidem, Meditación primera, § 8, p. 25. Cfr. también Ideen zu einer reinen Phänomenologie und phänomenologischen Philosophie, HuaIII, Den Haag, Martinus Nijhoff, 1950. Citaremos esta última obra por la siguiente versión en español: Ideas relativas a una fenomenología pura y una filosofía fenomenológica, México, F. C. E., 1949, §§ 33-37 y 47-50, pp. 75-85 y 108-116. Traducción de José Gaos. En adelante, citaremos como Ideas $I$.

${ }^{9}$ Meditaciones cartesianas, Meditación primera, § 10, p. 34.
} 
sería asunto de las ciencias positivas, como la biología, la antropología o la psicología. ${ }^{10}$ Se trata - como veremos- del ego puro o yo trascendental, que a diferencia del kantiano no es sólo una condición formal del conocimiento, sino una condición del significado del mundo mismo en cuanto fenómeno.

\section{EL PROBLEMA DEL FENÓMENO ORIGINARIO}

Sin embargo, esa vuelta neocartesiana al sujeto la lleva a cabo una filosofía que paradójicamente se designa a sí misma aludiendo a aquello que constituye el contrapunto del yo: al fenómeno u objeto de la conciencia. Esa vuelta al sujeto es al mismo tiempo una vuelta al fenómeno que se presenta a la conciencia como lo contrapuesto a ella. Esto es lo que se recoge en la famosa consigna de "ir a las cosas mismas" ("Zu den Sachen selbst"11 ${ }^{11}$ ), que no ha de entenderse como una máxima que preconice la vuelta al realismo precrítico de la gnoseología premoderna. Por el contrario, esta consigna impulsa la filosofía de Husserl en el sentido del idealismo, puesto que las cosas mismas no son sino las cosas tal como se hacen presentes en mi conciencia y para ella, y una vez que ésta se ha desprendido de los añadidos que en mi manera de ver incorporan la tradición, los supuestos teóricos o el sentido común (la actitud natural). Las cosas mismas son entonces el resultado de una depuración de estos aditamentos exteriores que se interfieren en mi modo puro de considerarlas y me impiden apreciarlas tal como son en sí mismas, en su puro darse. Ir a las cosas mismas no es, por lo tanto, abogar por la actitud natural, que es nuestra forma habitual de experimentarlas envueltos en la doxa, sino que entraña un movimiento de vuelta al origen para desentrañar lo que ellas son con antelación a la "tesis general de la actitud natural", neutralizando por lo tanto el sentido tético o "fuerza dóxica" (la pretensión de realidad separada o existencia independiente de las cosas que aparecen como fenómenos) que dicha actitud comporta: esas cosas mismas no son finalmente sino su puro darse en cuanto fenómenos de la conciencia. Esa vuelta a las cosas, en fin, es el proyecto mismo del método fenomenológico, que se hace efectivo mediante el proceso de la reducción, a través

${ }^{10}$ Ibidem, Meditación primera, § 11, p. 35.

${ }^{11}$ Esta máxima expresa el sentido de la fenomenología, según la consideración sobre la misma que desarrolla Heidegger en el $\S 7$ de Sein und Zeit, Tübingen, Max Niemeyer, 2001, pp. 27ss. 
del cual la identidad de las cosas se aproxima incesantemente, a la manera de una asíntota, a su sentido instituido por la conciencia.

Quizás la fórmula más apropiada para indicar esta tarea que se propone la fenomenología no sea la de volver a las cosas mismas, sino más bien la que expresa el imperativo de captar el fenómeno en su pura radicalidad: el fenómeno originario. De este modo, el esfuerzo filosófico de Husserl se inscribe en una larga tradición que se remonta a los antiguos griegos: a la consideración de los presocráticos, según la cual la naturaleza de las cosas yace oculta bajo sus aspectos visibles; o a la noción de Heráclito, de acuerdo con la cual la armonía invisible es más real que lo que se exhibe inmediatamente en el fenómeno, el cual aparece y oculta al mismo tiempo; o a la doctrina de Parménides, quien también ve en el fenómeno la apariencia múltiple y sensible que oculta el ser; etc. Esta tradición - por no hablar de los pitagóricos- se prolonga con la búsqueda platónica de las Formas inteligibles, así como con el primado de la ousía en Aristóteles y, a través de la metafísica cristiana, alcanza una nueva reformulación en el racionalismo moderno, que vincula el fenómeno a lo que se hace presente a la conciencia ${ }^{12}$. Por lo tanto, la posición dominante en la tradición filosófica confiere en general un significado peyorativo a la noción de fenómeno, asociada a la idea de una apariencia encubridora y engañosa, además de inconsistente y fugitiva. La ciencia moderna, por su parte, impondrá una nueva manera de considerar los fenómenos, con su renuncia a la pretensión metafísica -identificada con la tradición aristotélica- de conocer una esencia oculta tras los mismos, aunque esa nueva atención a los fenómenos y la consiguiente valoración de la experiencia que comporta no es óbice para que la ciencia se plantee la tarea de "salvar las apariencias" y encontrar leyes que, formuladas en los términos de las matemáticas, den explicación de lo que los fenómenos por sí solos no pueden explicar. Pero en el plano filosófico es Kant quien ofrece un nuevo enfoque, en cuanto vincula el fenómeno con una nueva manera de entender la objetividad. El fenómeno no es para él mera apariencia subjetiva, sino el modo objetivo de presentarse las cosas a la conciencia según las formas de intuirlos en el espacio y en el tiempo. De este modo, su fundamentación del conocimiento lo desmarca de la metafísica sin verse por ello abo-

\footnotetext{
12 Fernando Montero hace un resumen de esa historia de la noción de "fenómeno" en su libro $R e-$ torno a la fenomenología, Barcelona, Anthropos, 1987, pp. 67ss, poniendo de manifiesto los sentidos del término entre los griegos y siguiendo su evolución hasta el giro que impone Kant.
} 
cado al fenomenismo subjetivista de Hume. Pero ese modo kantiano de considerar los fenómenos como lo que aparece objetivamente a la conciencia desde lo que las cosas puedan ser en sí mismas implica la idea de una esencia que se expresa en el fenómeno -y no sólo se esconde tras él-, o que éste es un aparecer de y desde aquello que constituiría su esencia (de ella, según Kant, sólo se conoce su fenómeno, en tanto éste es precisamente Erscheinung). Así, en efecto, lo concibe Hegel también cuando en la Ciencia de la lógica examina la dialéctica del fenómeno y la esencia, siguiendo el impulso metafísico del idealismo alemán, que trata de rebasar el límite establecido por Kant respecto de la cosa-en-sí en su afán por recuperar para la filosofía la tarea de conocer lo absoluto.

En relación con esta historia del sentido del fenómeno, Husserl adopta la posición típicamente moderna de comprenderlo como el darse de las cosas a la conciencia. Y a su manera recupera el enfoque kantiano, sólo que depurado de la dicotomía de forma y contenido, cuya crítica desarrolló el idealismo alemán. Esa distinción de forma y contenido, por otra parte, está asociada a una manera de entender el conocimiento según el tipo de apriorismo kantiano. Pero para Husserl la actividad de la conciencia no consiste en las formas con que ésta capta el objeto en general, sino en la intencionalidad, de tal manera que - de acuerdo con el impulso crítico de Kant- el objeto se nos revela siempre referido al acto intencional del sujeto. Mediante esta noción, sin embargo, se aparta de la tentación de comprender en términos dialécticos la relación sujeto-objeto y recupera un recurso teórico procedente de la escolástica, renovado por Brentano y reinterpretado por él mismo en la línea moderna que insiste en la actividad de la conciencia. Pero además la fenomenología no restringe el campo de los fenómenos a lo dado inmediatamente en la sensibilidad. Hay otros aspectos de la realidad que se exhiben ante la conciencia y pueden hacerse evidentes a ésta. También aquí Husserl recupera la posición cartesiana en cuanto a la intuición, que no se limita a los datos sensibles, sino que puede tener por objeto todo cuanto pueda ser dado a la conciencia.

La tarea que se propone la fenomenología es, por lo tanto, la de captar el fenómeno originario. Pero el problema estriba precisamente en aquello que se presenta como solución, pues en definitiva ¿qué es un fenómeno originario? ¿En qué consiste eso originario que convierte al fenómeno finalmente en una especie de presencia absoluta y que permite a Husserl sostener que supera la dis- 
tinción kantiana entre el fenómeno y la cosa-en-sí? Porque si el fenómeno se presenta ante la conciencia, ¿no se convierte por ello mismo en algo relativo a ésta perdiendo así su carácter puro u originario? ¿No es esto un callejón sin salida por cuanto la determinación del carácter originario de un fenómeno, convertida en asunto de la conciencia, convierte a aquél precisamente en nooriginario? ¿O es, por el contrario, la conciencia la que se atiene sin más al fenómeno sin añadir ni quitar nada de su parte? Aquí se halla un problema fundamental de la filosofía de Husserl, cuya respuesta es decisiva en relación con la cuestión del sujeto. $Y$ en rigor estas últimas preguntas, así formuladas, distorsionan el enfoque de Husserl, porque presuponen el dualismo de cuño kantiano entre el fenómeno y la cosa, cuyo rechazo radical es precisamente la seña de identidad de toda su filosofía. Por eso, la cuestión del fenómeno originario y la cuestión del yo puro no son sino aspectos de una misma y única tarea, de tal manera que la dilucidación de lo que sea el fenómeno originario nos devuelve a la cuestión del yo: el fenómeno es aquello que aparece a la conciencia y sólo se da en ella, y corresponde a ésta - según Husserl- determinar cuál es su auténtico sentido originario. $Y$, sin embargo, en la experiencia que hace del fenómeno, esa misma conciencia capta que hay algo inmanente en esa experiencia que remite a lo que está fuera de la conciencia, a una materia (hylé) con la que se topa inicialmente el yo en su esfuerzo activo por constituir el sentido de la cosa en tanto ésta es reducida a puro fenómeno. Sin embargo, esos contenidos sensibles en cuanto se integran en una vivencia son asumidos por la conciencia como parte del nóema ${ }^{13}$. Ahora bien, no se trata de cualquier tipo de conciencia, sino de aquélla que pertenece a un yo puro.

\section{DEL yo NATURAL AL YO TRASCENDENTAL}

Esa vuelta al sujeto, que sigue el ejemplo de Descartes, se lleva a cabo a partir de la actitud crítica que la filosofía - sobre todo desde Kant - ha adquirido respecto de las estructuras del yo, en el cual la fenomenología reconoce diversos planos de profundidad. Y, por otro lado, en el camino metódico hacia el ego cogito y sus cogitationes, el método fenomenológico sustituye el recurso de

${ }^{13}$ Vid. Ideas I, § 97, p. 237. 
la duda escéptica por el de la abstención de la conciencia, que deja en suspenso todo lo que no es apodícticamente evidente $y$, por ende, encierra algún momento de presunción. El propio Husserl compara esta actitud, que denomina "epoché", con "el intento de dudar", en cuanto que en ambos, y a través de un acto de mi absoluta libertad, se produce una especie de abolición de la tesis que implícitamente siempre acompaña a la experiencia inmediata, según la cual las cosas que se me aparecen tienen una realidad propia que coincide con la manera en que me las represento habitualmente, lo cual entraña la suposición de que el mundo que está ahí delante tiene una existencia independiente de míl $^{14}$. La abolición de dicha tesis es la superación de la actitud natural, que como dice Husserl- es la propia de la conciencia común, que vive en la seguridad del mundo y según la opinión corriente. El conjunto de la fenomenología se puede entender precisamente como la tarea filosófica que lleva a cabo la superación de la actitud natural por parte de la actitud fenomenológica, que denuncia los tributos que aquélla rinde a la opinión común. Pues bien, esa actitud, que comparte las creencias de la conciencia común, se resume en lo que Husserl denomina la "tesis general de la actitud natural"15, a saber: que el mundo está siempre ahí como realidad independiente compuesta por los objetos de la experiencia.

Lo que hace la epoché es "aniquilar el mundo"16, en el sentido ya mencionado de abolir el carácter "tético" de la actitud natural, y no por cierto para sustituir su tesis por una antítesis, sino para dejarla en suspenso o colocarla entre paréntesis. "Epoché" tiene, por lo tanto, ese sentido negativo de suspensión del juicio para no añadir nada al puro mirar ${ }^{17}$. Se trata en rigor del momento negativo de la llamada "reducción fenomenológica", que constituye el auténtico núcleo del método de Husserl y que obedece al impulso filosófico de "volver a las cosas mismas", un proyecto que tras aquel momento negativo de la suspensión del juicio encierra además un momento positivo, consistente en

${ }^{14}$ Ibidem, §§ 31-32, pp. 69-74.

${ }^{15}$ Ibidem, § 30 , pp. 68s.

${ }^{16}$ Ibidem, § 49, pp. 112ss.

17 Javier San Martín destaca ese sentido negativo que comporta la epoché, en cuanto limitación (Einschränkung), abstención (Enthaltung), desconexión (Ausschaltung) o eliminación de todo prejuicio, que supone una "puesta entre paréntesis" (Einklammerung) y un "echarse para atrás" (Zurückhaltung) para mirar. Vid. Javier San Martín: La estructura del método fenomenológico, Madrid, Universidad Nacional de Educación a Distancia, 1986, p. 28. Vid. también Ideas I, § 32, p. 73. 
la retención de aquello a lo que me he limitado y a lo que ahora positivamente- atiendo ${ }^{18}$.

Ahora bien, aquel ego ante el que comparecen las cosas como fenómenos no es el yo natural (protagonista de la actitud natural), ni tampoco el yo psíquico sobre el que inciden causalmente las cosas mundanas generando en él una reacción subjetiva. Desde luego que ya en el plano de la experiencia ordinaria que caracteriza a la actitud natural cabe una reflexión del yo, y se trata entonces de una reflexión natural sobre nosotros mismos, que forma parte de nuestras vivencias cotidianas sobre lo que somos o hacemos. Esa actitud natural en cuanto reflexiona es capaz de distinguir la experiencia misma del sujeto como algo diverso del mundo experimentado. Si se hace de ello además ciencia, nos encontramos entonces en otro nivel de consideración que rebasa el propio de la actitud natural. En la perspectiva científica que define la psicología, el yo se nos presenta en oposición al mundo exterior o físico y constituido frente a éste como un ámbito de subjetividad o interioridad. $Y$ en este plano se nos revela que la vida mental tiene rasgos específicos que la diferencian de la esfera de la realidad física.

Por cierto que la consideración de la psicología por parte de Husserl fue titubeante, porque inicialmente (en Ideas I, por ejemplo) parece considerarla como una primera fase de la tarea fenomenológica, de tal manera que habría que hablar entonces de una fenomenología psicológica como previa a la fenomenología trascendental. Y en esa fase psicológica de la fenomenología habría a su vez que distinguir una epoché psicológica (la que se abstiene de entrar a considerar el lado físico de los fenómenos) y una reducción psicológica (la que tras aquella abstención se limita a atender a los fenómenos psíquicos o subjetivos). Sin embargo, posteriormente (en las Meditaciones cartesianas, por ejemplo) se inclina por considerar a la psicología como un nivel de análisis de los fenómenos previo al que caracteriza a la filosofía, cuya tarea entonces se identifica con la fenomenología trascendental, que se sirve de la reducción fenomenológica en su doble vertiente de la reducción trascendental y la reducción eidética.

${ }^{18}$ Ideas $I, \S 50$, pp. 115s. También el profesor San Martín se refiere a la reducción llamando la atención sobre su doble sentido: el negativo, o epoché, y el positivo, que implica retención y atención, con el matiz añadido de "reconducción" (Züruckführung) y de vuelta a las cosas mismas como vuelta a lo original (Rückgang auf). Vid. La estructura del método fenomenológico, pp. 28s y 37s. 
En cualquier caso, el análisis de la vida psíquica - dejando ahora de lado la crítica al psicologismo desarrollada en las Investigaciones lógicas- siempre presentó un gran interés para Husserl, como preludio de la reflexión fenomenológico-trascendental. En particular, se interesó por el modo en que ya en el nivel del psiquismo -que es anterior al propiamente trascendental- se hace presente ese rasgo de la conciencia que denomina - siguiendo a Brentano"intencionalidad". Es decir: el carácter de la conciencia de ser conciencia de algo, de hacer referencia a algo hacia lo que apunta la propia vivencia ${ }^{19}$. En el terreno de lo psíquico, concretamente, la intencionalidad tiene el carácter de la implicación, que es lo mismo que decir que los fenómenos psíquicos se relacionan entre sí de manera interna, porque las vivencias del yo psíquico son experiencias que implican posibilidades de otras experiencias. Y esta consideración nos permite volver sobre lo que antes señalábamos acerca de los rasgos específicos de la vida mental. En efecto, Husserl destaca que, así como las relaciones entre los fenómenos físicos son externas (pues son relaciones de coexistencia, resistencia o causalidad), por el contrario, en la esfera psíquica las relaciones entre los fenómenos son internas, pues se trata de relaciones de implicación. Esa intencionalidad como implicación, característica de la vida subjetiva, se pone de manifiesto cuando consideramos, frente a la espacialidad del mundo físico, la temporalidad de acuerdo con la cual se constituye la vida subjetiva. En este sentido, Husserl distingue entre el tiempo cosmológico u objetivo y el tiempo fenomenológico, cuyos momentos no son extrínsecos entre sín ${ }^{20}$.

Ahora bien, la reflexión sobre el yo en el terreno de la psicología no logra desprenderse de la conceptualidad natural y, en ese sentido, no escapa del todo a la actitud natural. La reflexión fenomenológica, por lo tanto, no puede detenerse en este plano de análisis, sino que buscará un ego más originario que el yo psico-físico, un ego cuya experiencia no esté referida al ser natural del mundo, porque en tal caso seguiría tratándose de un yo mundano. Esta forma mundana de entender la subjetividad se encuentra además enredada en una aporía que le resulta insuperable, y que es la aporía de la subjetividad humana, a saber: el hombre, en tanto sujeto, se representa el mundo contraponiéndolo

${ }^{19}$ Ideas $I, \S 36, \mathrm{pp} .81 \mathrm{ss}$ y $\S 84, \mathrm{pp} .198 \mathrm{ss}$.

${ }^{20}$ Ideas $I, \S \S 81-83$, pp. 191ss. Sin embargo, el análisis que aquí desarrolla Husserl sobre el tiempo subjetivo se realiza en el nivel fenomenológico-trascendental y no en el de análisis del yo psíquico. Pero lo dicho sobre la relación interior de implicación entre los momentos del tiempo valdría también en relación con la vivencia psíquica del mismo. 
a su conciencia al mismo tiempo que se sabe parte de él. En otros términos: tanto el mundo fenoménico captado como el propio sujeto psico-físico que lo experimenta pertenecen ambos a un mismo mundo real, el cual a su vez exigiría entonces un yo previo más originario que lo convirtiera en su tema. Pero si éste a su vez, junto con el mundo tematizado por él, pertenece también a un mundo más general que los envuelve a ambos, no conseguimos nunca superar el carácter aporético de semejante noción de la subjetividad ${ }^{21}$. A no ser que como hace Husserl- entendamos el yo originario, no como un yo mundano, sino como la condición de posibilidad del mundo mismo, es decir, como el ego trascendental, que es una noción que se nos impone de manera ineludible si es que queremos dar algún sentido a nuestra radical experiencia del mundo.

Esta es la vieja solución del idealismo, que Husserl asume como definición de su propia posición, que él mismo presenta como idealismo trascendental ${ }^{22}$. Sin embargo, desde una posición crítica con el idealismo, cabría argüir contra Husserl que no hay tal precedencia del yo, ni se produce tampoco la paradoja en cuestión, pues siempre cabe decir: el mundo me precede materialmente, aunque el yo precede a su idea del mundo. Sin embargo, Husserl no puede aceptar semejante posición debido al principio fundamental que inspira su pensamiento, de acuerdo con el cual la cosa misma se reduce una y otra vez a su puro darse a la conciencia en cuanto fenómeno. $Y$ aquí se hace patente que su idealismo radicaliza el punto de vista de Kant -también llamado, aunque con otro sentido, "idealismo trascendental"-: en efecto, para Husserl deja de tener sentido la distinción entre el fenómeno y la cosa en sí, que es una distinción que se hace insoslayable cuando - como hace Kant- se comprende el fenómeno -al menos en su contenido- como lo dado a la conciencia, por decirlo así, desde afuera, en calidad de material sensible, dato o contenido que se le impo-

${ }^{21}$ Se trata de la formulación de una paradoja cuya versión más clásica aparece ya en el idealismo moderno, desde Spinoza, como una paradoja del conocimiento: ¿cómo puede el conocimiento estar cierto de su adecuación a los objetos conocidos si éstos se encuentran frente al sujeto que conoce? Si el conocimiento parte de la oposición de sujeto y objeto, ¿cómo puede el sujeto trascenderse en el objeto conocido? ¿Cómo puede ser al mismo tiempo el yo y el no-yo? ¿Cómo puede el yo del conocimiento ser a la vez el sujeto que conoce y el objeto conocido? En estos términos se expresa el propio Husserl en Die Idee der Phänomenologie, Den Haag, Martinus Nijhoff, 1950; versión en español: La idea de la fenomenología. Cinco lecciones, México, F. C. E., 1982, pp. 27ss. Traducción de Miguel García-Baró. Vid. también Javier San Martín, La estructura del método fenomenológico, pp. 135ss, donde dicha aporía se plantea también en otros términos: el sujeto humano - nos dice- sólo vive por y para el mundo, del cual sin embargo sólo sabe por la representación — subjetiva- que tiene de él; también insiste en que dicho carácter aporético no sólo afecta a la subjetividad psíquica, sino también al mundo que ella se representa: en efecto, en el mundo representado, y como parte de él, se da el mundo que incluye al sujeto de esa representación.

22 Meditaciones cartesianas, Meditación cuarta, § 41, p. 114. 
ne, tan sólo a partir del cual puede proceder aquélla a través de las formas que intuyen o piensan dicho contenido fenoménico. Esta posición entraña la noción de una cosa-en-sí cuya realidad se encuentra más allá de lo que aparece como dato para la conciencia. Por su parte, Husserl rechaza que se pueda hablar con sentido de un dato que la conciencia haya de admitir como algo impuesto externamente a ella de modo absoluto, de la misma manera que tampoco puede hablarse con sentido de una cosa en sí, puesto que todo dato y toda cosa tienen un sentido sólo en cuanto lo son para o de la conciencia. Ahora bien, esto no se puede entender adecuadamente sin hacernos cargo de su concepto de la intencionalidad, de acuerdo con la cual el objeto es siempre el objeto-de la conciencia.

Pero, de momento, digamos que la reducción, en su versión trascendental, se atiene al puro fenómeno como una vivencia de la conciencia a la que se ha despojado de todo aditamento extrínseco a su puro fluir. $Y$ el descubrimiento del yo trascendental se produce - según Husserl- a través de una reflexión que parte del fenómeno tal como éste se revela tras la epoché y la reducción llevadas a cabo por el método fenomenológico trascendental: no es el yo que corresponde al fenómeno psíquico, sino aquél que se concibe como condición de posibilidad de toda experiencia, en la cual además el objeto experimentado ha sido reducido a su puro carácter fenoménico, de acuerdo con una actitud que se abstiene de juzgar sobre la existencia real independiente de dicho objeto. 0 , como dice Husserl, "sin que nosotros, en cuanto sujetos que reflexionan, coejecutemos la posición natural del ser que está contenida en la percepción originariamente llevada a cabo de modo directo" ${ }^{23}$. De modo que:

El no co-ejecutar, el abstenerse del yo en la actitud fenomenológica, es cosa suya, y no cosa del percibir considerado reflexivamente por él. [...] Así pues, si llamamos interesado en el mundo al yo que de modo natural realiza sus experiencias en el mundo y vive inmerso en él $[\ldots]$, sobre el yo ingenuamente interesado se establece el yo fenomenológico como espectador desinteresado. ${ }^{24}$

Pero esto último es accesible tan sólo a una nueva reflexión: la fenomenológico-trascendental. Así pues:

${ }^{23}$ Ibidem, Meditación segunda, § 15, p. 48.

${ }^{24}$ Ibidem, p. 49. 
Por la epoché fenomenológica yo reduzco mi yo natural humano y mi vida psíquica -el reino de mi experiencia psicológica de mí mismo a mi yo fenomenológicotrascendental, al reino de la experiencia fenomenológico-trascendental de mí mismo. El mundo objetivo que para mí existe [...] extrae todo su sentido y su validez de ser $[\ldots]$ de mí en cuanto yo trascendental $[\ldots] .{ }^{25}$

Es el yo trascendental, por lo tanto, el que instituye todo sentido, de acuerdo con la doctrina de la intencionalidad constituyente.

\section{LA INTENCIONALIDAD CONSTITUYENTE DEL EGO}

Ya hemos señalado que la vida psíquica - según la conocida concepción de Husserl- presenta ese rasgo singular que consiste en hacer referencia a algootro, pues la vida mental no se cierra en sí misma, sino que tiende (intendit) hacia aquello (la cosa percibida, el objeto deseado, la situación añorada en el recuerdo, etc.) en función de lo cual se constituye el fenómeno psíquico de que se trate. Pero esa tensión por cuya virtud la conciencia apunta fuera de sí hacia algo que reconoce al mismo tiempo como suyo y como diverso de sí, esa intentio, es un carácter esencial del yo, no sólo en cuanto sujeto psíquico, sino en general como definición del modo mismo de ser del yo. Es decir, la determinación de la actividad como rasgo esencial de la realidad humana por parte de la modernidad adquiere en Husserl y en su filosofía de la conciencia el significado de la intencionalidad. Pero, al mismo tiempo, toda la teoría de la intencionalidad entraña el rechazo de la consideración sustancialista del yo y supone igualmente plantear la relación yo-mundo en términos que se apartan radicalmente del dualismo de las sustancias.

En efecto, en el pensamiento de Husserl se concibe el ego en su raíz última como la fuente del sentido en general, lo cual equivale a decir: el yo es la razón última del ser de las cosas en cuanto fenómenos, ya que -como hemos visto antes a propósito de la comparación con Kant- no hay nada que se le imponga como dato absoluto ya constituido ${ }^{26}$. Ahora bien, ese ego radical es el yo trascendental, en tanto lo concebimos precisamente como la fuente última de do-

${ }^{25}$ Ibidem, Meditación primera, § 11, p. 36. Vid. también Meditación segunda, § 15, pp. 48ss.

${ }^{26}$ Aunque aquí hay que matizar que esa actividad de la conciencia se topa con los "datos hyléticos" que constituyen pasivamente la cosa en su materialidad, no obstante lo cual esa materia por sí sola no constituye aún sentido alguno. Esto nos remite a la noción de la constitución pasiva, de la que nos ocuparemos más adelante. 
nación de sentido. Conviene precisar a este respecto que no hay diferentes yoes - un yo natural, un yo psíquico, un yo trascendental-, sino diferentes planos de profundidad o de consideración del yo, cuyas diversas actitudes son otras tantas maneras distintas de experimentar - desde el nivel natural hasta la experiencia trascendental. También en este punto se alejó Husserl del dualismo kantiano sobre el sujeto empírico y el sujeto trascendental.

La intencionalidad característica del ego trascendental no remite a una realidad empírica independiente, porque la reducción fenomenológicotrascendental ha inhibido todo juicio acerca del ser real, posible o conjetural del objeto en cuestión, limitando su consideración a aquello que se da en su puro aparecer, depurado de consideraciones extrínsecas a lo que se muestra en el fenómeno. Esto explica el significado de la intencionalidad para Husserl, quien se acogió a un uso de este término proveniente de Brentano (quien, a su vez, se había hecho eco del empleo de dicho término en el campo moral y gnoseológico por parte de la filosofía medieval), al cual le imprimió sin embargo una nueva significación. Porque el reconocimiento de la intencionalidad como un a priori de la conciencia por parte de Brentano ${ }^{27}$ está asociado en él todavía con el supuesto realista que atribuye entidad independiente al objeto, del cual la conciencia - según ese supuesto- se forma una representación en tanto aquél incide causalmente sobre ésta y produce un efecto en ella. De tal manera que, de acuerdo con esta interpretación de origen escolástico, cabe decir que la conciencia termina reproduciendo en su seno el ser mismo del objeto, aunque no realmente sino sólo intencionalmente. Husserl, por su parte, rechaza el supuesto realista de esa "intencionalidad receptiva" - que por otra parte no cambiaba nada sustancialmente en la concepción del conocimiento respecto de los viejos planteamientos del realismo gnoseológico- mediante el descubrimiento de lo que se ha llamado "el a priori de correlación intencional universal"28, según el cual de la misma manera que toda conciencia es siempre conciencia-de un objeto, todo objeto a su vez, en cuanto dado a ella, es objeto-de una concienciade. Es decir: así como no hay conciencia clausurada que pueda entenderse sin referencia a los objetos, tampoco éstos están cerrados o son independientes

\footnotetext{
27 Para Brentano en concreto la intencionalidad es el carácter descriptivo fundamental de los fenómenos psíquicos. Husserl se refiere a este descubrimiento de Brentano al mismo tiempo que señala sus insuficiencias: Ideas $I$, § 85, p. 205; § 129, pp. 309s; y § 6 del epílogo, pp. 388-390; también Meditaciones cartesianas, Meditación segunda, § 17, p. 57.

${ }^{28}$ Vid. Javier San Martín, La estructura del método fenomenológico, pp. 223ss.
} 
respecto de la subjetividad intencional. El objeto es siempre el objeto intencional, de manera que, según esta doctrina, no tendría sentido la noción de la cosa-en-sí tal como la entiende Kant, pues eso supondría aceptar que hay un sentido de la cosa fuera de la conciencia.

Esta concepción de la intencionalidad da la clave del idealismo de Husserl, en el que no cabe una idea de realidad que trascienda de manera absoluta a la conciencia misma. Este idealismo es el descubrimiento sistemático de la intencionalidad constituyente misma ${ }^{29}$. Es verdad que él no niega el significado que pueda tener la noción de la materialidad de las cosas, como tampoco pone en cuestión la existencia de los otros con su propia vida subjetiva al margen de la mía, pues no es el suyo un idealismo en el sentido de Berkeley ${ }^{30}$. Sin embargo, sostiene que el sentido de esas realidades sí ha de originarse en algún sustrato de la conciencia para que quepa decir que forman parte de mi experiencia: "[...] el mundo mismo tiene todo su ser como un cierto 'sentido' que presupone la conciencia absoluta como campo del dar sentido" ${ }^{\prime 31}$.

Y esto último nos permite volver sobre lo dicho anteriormente a propósito de la inhibición de realidad o existencia presente en la actitud natural. Pues esa inhibición, aun cuando se opone al realismo ingenuo que acompaña a la actitud natural, no anula sin embargo que la pretensión óntica del objeto en cuestión esté de algún modo presente en la forma peculiar de su exhibición en la conciencia. De tal manera que en dicha exhibición pueda admitirse que contiene algo cuya entidad, en virtud de la forma en que lo capta la conciencia, trasciende lo que de él se muestra de modo inmediato. Lo que trasciende al fenómeno como tal se hace de algún modo presente en su expresión inmanente; así pues, la pretensión de realidad del fenómeno está ínsita en él, en su forma de darse, pero ahora no ya en el sentido de la actitud natural, sino como algo que se halla en el fenómeno "reducido" por el yo trascendental. Dicho de otro modo: experimento un mundo que se extiende fuera de mí, y en esa medida me hago cargo de su trascendencia, pero ésta ha de estar necesariamente prefigurada en el yo, en cuanto es éste el que tiene la experiencia de una realidad que le trasciende. Por eso emplea Husserl la problemática expresión "trascendencia en la inmanencia", mediante la cual trata de expresar que, aun cuando el yo puede

\footnotetext{
${ }^{29}$ Meditaciones cartesianas, Meditación cuarta, § 41, p. 114.

${ }^{30}$ En Ideas I, § 55, pp. 129ss critica explícitamente el "idealismo subjetivo" de Berkeley.

31 Ibidem, p. 130.
} 
considerar la noción de un objeto trascendente, el objeto en cuestión es algo para la conciencia $y$, en cuanto tal objeto intencional, su sentido ha de estar necesariamente instituido en su origen por la actividad intencional del ego trascendental, pues hay que tener en cuenta que:

[...] todo lo que es para ese ego puro se constituye en él mismo y, además, que toda clase de ser, comprendido aquél caracterizado como trascendente en algún sentido, tiene su constitución particular. La trascendencia en todas sus formas es un carácter inmanente del ser que se constituye en el interior del ego. Todo sentido, todo ser concebible, se llame inmanente o trascendente, cae dentro del ámbito de la subjetividad trascendental en cuanto aquella que constituye el sentido y el ser. ${ }^{32}$

A este respecto conviene precisar que esa ambigua referencia al sentido y al ser se debe a que, finalmente, ambos coincidirían: en una aproximación asintótica que se llevara idealmente hasta el límite, el ser al que apunta la conciencia no se diferenciaría ya del sentido que ella funda para él; sólo que ese límite es inalcanzable de hecho. Pero lo que está aquí en cuestión es el concepto mismo de intencionalidad, que implica que el ser de la cosa captada no está como tal dentro de la conciencia, pues lo que es inmanente a ésta no es sino la vivencia de la cosa: "No puede darse una cosa en ninguna percepción posible, en ninguna conciencia en general posible, como inmanente en el sentido de ingrediente. Una distinción de esencial radicalidad resalta, así, entre el ser como vivencia y el ser como cosa ${ }^{33}$.

Sin embargo, estas últimas palabras no dan cuenta suficientemente del sentido que presta Husserl a la intencionalidad, pues si se tratara sólo de la distinción entre el ser real y el ser como vivencia no habríamos ido más allá del significado que le presta Brentano y, antes que él, la escolástica. Husserl le añade otro sentido, de acuerdo con el cual el ser trascendente de la cosa se da en el modo mismo de aparecer ésta: en efecto, en la forma en que se presenta el objeto intencional en la vivencia correspondiente, y según la manera en que ese objeto se "matiza" o "escorza"34, él mismo se nos aparece como algo trascendente que se da a la conciencia de manera inmanente; es decir, incluso cuando se trata de lo trascendente, se trata de un modo determinado de apare-

32 Meditaciones cartesianas, Meditación cuarta, § 41, p. 111. Vid. también Meditación quinta, §§ 47,48 y 49 , pp. $138-144$.

Ideas I, § 42, p. 95.

${ }^{34}$ Ibidem, p. 96. 
cer o de darse a la conciencia y, en tal sentido, sigue siendo inmanente a ella en cuanto cae en una vivencia intencional:

\begin{abstract}
El ser del mundo es de esta manera [...] trascendente a la conciencia y sigue siéndolo necesariamente; pero ello no cambia en nada el hecho de que sea únicamente la vida de la conciencia aquella en la cual todo lo trascendente se constituye como inseparable de ella y que ella, tomada especialmente como conciencia del mundo, lleve inseparablemente en sí el sentido mundo e incluso este mundo que realmente existe. En última instancia es únicamente el descubrimiento de los horizontes de la experiencia el que aclara la realidad efectiva del mundo y su trascendencia, y luego lo muestra como inseparable de la subjetividad trascendental que constituye el sentido y la realidad del ser. [...] Un objeto real del mundo y con más razón el mundo mismo es una idea infinita, referida a infinitudes de experiencias que han de ser unificadas de modo concordante - una idea que es el correlato de la idea de una evidencia perfecta de la experiencia, o sea, de una síntesis completa de las experiencias posibles. ${ }^{35}$
\end{abstract}

Esto se hace posible en virtud de lo que ya en las Lecciones de 1910-11, conocidas y publicadas como Problemas fundamentales de la fenomenología, denomina Husserl la "distinctio phaenomenologica" o distinción entre el ser empírico y el ser fenomenológico de las $\operatorname{cosas}^{36}$, distinción inevitable cuando, llevados por la actitud fenomenológica, "desconectamos" la pretensión de existencia de lo que constituye el contenido de nuestra vivencia. En ese mismo texto, y en relación con lo que pertenece a la realidad que trasciende a la experiencia, leemos unas aseveraciones que aclaran el significado que presta Husserl a su fórmula de la "trascendencia en la inmanencia":

\begin{abstract}
Hablamos, y con evidente derecho, de un ser-en-sí de las cosas frente al conocimiento y la conciencia [...] Hablando de un modo científico-natural, esto es correcto [...] El ser dado en la experiencia no se deshace en el percipi, sino que más bien es un en-sí frente a él, y un en-sí que llega a darse, pero sin que, por principio, se dé nunca de modo absoluto; su mención sigue siendo sólo una mención en el sentido de que necesita de una prueba que nunca se ha de dar definitivamente. Con ello, el en-sí de la cosa es siempre pretensión frente al conocimiento, en la medida en que nunca abandonamos la conciencia de experiencia [...] La cosa se da en la experiencia y, sin embargo, de nuevo no se da, pues justamente su experiencia es donación a través de exposiciones y "fenómenos". 37
\end{abstract}

Es decir: lo dado en la experiencia, en cuanto fenómeno inmanente a la conciencia, apunta más allá de lo expuesto en esa donación y mienta en sí mismo aquello de la cosa que no se da y queda fuera de la conciencia. Precisa-

${ }^{35}$ Meditaciones cartesianas, Meditación tercera, § 28, pp. 82s.

${ }^{36}$ Edmund Husserl, Problemas fundamentales de la fenomenología, Madrid, Alianza Universidad, $1994, \S 13$, pp. 79ss. Traducción de César Moreno y Javier San Martín.

${ }_{37}$ Idem. 
mente el concepto de Naturaleza es el de lo que, por principio, sobrepasa la experiencia y no puede darse de modo absoluto en ella ${ }^{38}$.

Ahora bien, hay que decir igualmente que tampoco la conciencia tiene una realidad absoluta separada de los objetos a los que está intencionalmente referida. Toda conciencia, según hemos visto, es siempre conciencia-de un objeto. Y a partir de esta última afirmación resulta entonces problemático comprobar que Husserl sí habla en ocasiones de la conciencia como de un absoluto ${ }^{39}$. Conviene a este respecto hacer alguna matización. En primer lugar, hay que hacer notar que la conciencia -según Husserl- define el horizonte de toda presencia, lo cual hace de ella en cierto modo un absoluto, incluso aceptando que esa presencia puede remitir a algo que le es ajeno. Pero, en relación con esto último, y en segundo lugar, hay que precisar que, según Husserl, aun cuando la conciencia no alcanza a anular del todo la alteridad de las cosas, sí tiende siempre a apropiarse de dicha alteridad -y a "reducirla" en ese sentido- cuando una y otra vez instituye o explicita un sentido para la cosa. Es éste un momento decisivo de la fenomenología, que nos permite entender su compromiso con el idealismo, pues en definitiva descarta la posibilidad de una alteridad absoluta para la conciencia, en cuanto que eso que se nos presenta como algo-otro no puede tomar su sentido - según Husserl- más que de la actividad intencional de la conciencia ante la que aquello aparece. Todavía Kant reconoce los derechos de la alteridad irreductible al sujeto mediante su noción de la cosa-en-sí. Husserl, por su parte, trata de suprimir ese escollo de lo absolutamente otro respecto del sujeto, y lo hace por un camino distinto del seguido por el idealismo alemán: no a través de su comprensión como un momento del proceso de alienación del espíritu, sino - recuperando el motivo principal de la filosofía cartesiana- mediante la "reducción" de "eso otro" al fenómeno cuyo sentido establece la conciencia. Y aunque "aquello otro" no acabe nunca de reducirse del todo al significado con que ella lo capta, y perdure así un resto de alteridad en la cosa que le hace frente, el yo responde una y otra vez constituyendo el sentido que permite captar esa nueva presencia; y así sucesivamente en una tarea que no tiene fin, porque en definitiva: "la subjetividad trascendental [...] es el universo del sentido posible ${ }^{\prime 40}$.

\footnotetext{
${ }^{38}$ Ibidem, § 30, p. 105.

39 Vid. por ejemplo el texto ya citado de Ideas $I$, § 55, p. 129.

40 Meditaciones cartesianas, Meditación cuarta, § 41, p. 111.
} 


\section{LA VIDA PURA DE LA CONCIENCIA Y SU CARÁCTER BILATERAL}

La reducción trascendental nos ha limitado al campo de la experiencia, de acuerdo con ese nivel de consideración alcanzado por la fenomenología para el cual - tras la epoché correspondiente - la realidad misma tiende a identificarse con el fenómeno trascendental. Ahora bien, el análisis fenomenológico de ese campo trascendental de la experiencia lo presenta Husserl con un carácter bilateral, en el sentido de que a todo fenómeno así reducido -que no es ya el fenómeno en el sentido vulgar - le corresponde, en cuanto objeto intencional, algún modo de intencionalidad que lo constituye. Esa correlación es un rasgo universal de toda forma de conciencia, de manera que en ella hay que distinguir siempre entre el acto de la conciencia con su fuerza intencional, o "nóesis", y el objeto intencional en cuanto lo representado en la representación, o "nóema". Este último incluye lo pensado, lo conocido, lo imaginado, lo querido, lo que sé de una cosa, de tal manera que abarca la totalidad de la representación que tengo de algo, donde a su vez cabe distinguir el núcleo del nóema, que permanece idéntico en los diversos modos de conciencia en relación con un objeto representado, y otros aspectos aludidos, implicados, co-mentados, etc., respecto del mismo. En cualquier caso, el nóema forma parte de la conciencia y debe distinguirse de la cosa como tal, que en algún aspecto queda fuera de mi conciencia: su materia, aun siendo un ingrediente de la vivencia, queda fuera de la conciencia. Sin embargo, esta distinción plantea como problema de carácter último para la fenomenología el del acercamiento del nóema a la cosa misma más allá de la conciencia y nunca definitivamente absorbida por ésta. Parece que aquí la conciencia muestra el poder constante de autotrascenderse. Es el mismo problema al que antes nos referíamos a propósito de la trascendencia en la inmanencia y la posibilidad de absorber enteramente la alteridad de la cosa. Nos parece que ésta es una cuestión límite que orienta la tarea de la fenomenología y que, en definitiva, revela el sentido idealista $-y$ no realista, como pudiera hacer creer una interpretación superficial- de acuerdo con el cual se concibe la intentio. Pues la conciencia no renuncia a determinar el sentido de la cosa que se halla fuera de ella, sentido que sería finalmente - en una aproximación asintótica - idéntico al ser de la cosa; pero ello es así al precio de "re- 
ducir" la alteridad de la cosa al acto de conciencia por el que ésta constituye su sentido, según hemos visto antes.

En este punto conviene precisar la distinción que plantea Husserl entre la materia (hylé) y la forma (morphé). La corriente del ser fenomenológico (o sea, del ser que aparece a la conciencia una vez llevada a cabo la epoché y la reducción trascendental) tiene una capa material o hylé sensible y una capa de "animación formal". La primera está compuesta por los "contenidos de la sensación" (los datos de color, sonido, tacto, etc.), por los sentimientos sensibles (de placer, dolor, cosquilleo, etc.) y también por los elementos sensibles de la esfera de los impulsos. Estos "datos hyléticos" son componentes de vivencias concretas más amplias que en conjunto -dice Husserl- son intencionales, en cuanto que sobre esos elementos sensibles hay una capa "animadora" o formal que les da sentido, de manera que aquello sensible sólo a través de esta capa animadora llega a producir una vivencia intencional concreta ${ }^{41}$. En todo el dominio fenomenológico tiene un papel dominante "esta dualidad y unidad" de la hylé sensible y la morphé intencional, de materia y forma: "Los datos sensibles se dan como materia para conformaciones intencionales u operaciones de dar sentido en diversos grados ${ }^{\prime 42}$.

Lo que aporta lo específico de la intencionalidad de la conciencia y, junto con las materias, configura las vivencias, es lo que hace a la conciencia ser conciencia de algo, a saber: la nóesis. Los diversos actos noéticos constituyen lo específico del nus en el sentido más amplio del término ${ }^{43}$. De tal manera que las funciones noéticas son las diversas formas posibles de conciencia o modos de dar sentido, pues el material sensible es de suyo algo sin sentido. Por lo tanto, la conciencia es diversa de la materia, que de por sí carece de sentido y es irracional $^{44}$.

La fenomenología, en su más amplia universalidad, trata de averiguar cómo se constituyen en la conciencia los objetos de cualquier región y categoría (objetos ideales, físicos, culturales, etc.). Es decir, trata de determinar cómo las formas fundamentales de conciencia posible diseñan, por su propia esencia, todas las posibilidades del ser; y según qué leyes esenciales un objeto es el

\footnotetext{
${ }^{41}$ Ideas $I, \S 85$, p. 203.

${ }^{42}$ Idem.

${ }^{43}$ Ibidem, p. 205.

${ }^{44}$ Ibidem, § 86, p. 207.
} 
correlato de esas formas de conciencia. Por lo tanto, a partir de los elementos materiales o hyléticos, cabe buscar posibles hilos del tejido intencional, en cuanto funciones noéticas "animadoras" de ese material sensible. Husserl habla a este respecto incluso de la posibilidad de una hylética pura ${ }^{45}$. Pero, ¿no volvemos de este modo al planteamiento kantiano, que considera las formas como los diversos modos posibles de intuir o de pensar el objeto en general? La respuesta negativa que debe darse a esta interrogante se aclara si atendemos a la distinción materia-forma, combinándola con la oposición nóesis-nóema. La forma del objeto se correspondería con una función noética de la conciencia. De modo que la forma es algo del objeto intencional y está presente en el nóema de acuerdo con aquella función noética de la conciencia. Por su parte, la materia pertenece a la vivencia concreta como ingrediente, pues, en efecto, la vivencia incluye la referencia a los datos hyléticos, aunque sean exteriores a la conciencia. Por lo tanto, por principio, la hylé queda fuera de las funciones noéticas y, por lo tanto, trasciende al nóema. Sin embargo, esta tajante afirmación es corregida en parte por Husserl, en cuanto señala que lo que en lo hylético se "exhibe" o "matiza" como múltiple sí pertenece al nóema, y entonces, en cuanto éste es siempre el correlato de alguna nóesis, cabría hablar incluso no sólo de formas noéticas, sino también de "materias noéticas ${ }^{46}$. Es decir, la constitución del ser de la cosa alcanza incluso en parte a su materialidad, en la medida en que dentro de ella hay aspectos que se deslindan de su pura presencia bruta, aspectos con los que el yo se adelanta a su captación. He aquí de nuevo esa idea límite de Husserl, según la cual el sujeto se anticipa a la materia trascendente del mundo, delineándola de antemano en alguno de sus aspectos, aunque pese a todo subsista siempre en las cosas reales un lado macizo e inabsorbible.

Pero, en definitiva, toda donación de sentido se ha de originar necesariamente en el ego primigenio. Por eso, a la objeción planteada por la hermenéutica cuando muestra que para toda conciencia hay siempre ya sentidos constituidos que ella se encuentra y que se le imponen de antemano, sin que en su origen ella contribuyera a configurarlos, hasta el punto que cabría decir que toda conciencia empieza a andar a partir de un estado de cosas en donde todo

${ }^{45}$ Ibidem, pp. 208s.

${ }^{46}$ Ibidem, § 97, pp. 237s. 
está ya interpretado; ante esa objeción -repito-, Husserl indicaría que dicho sentido supuestamente previo en rigor no sería tal para la conciencia en cuestión hasta que ésta se apropiara de él y lo hiciera suyo, contribuyendo de paso de esta manera a configurar el sentido de un mundo común compartido. Husserl no ignoraba el carácter objetivo y supraindividual de la tradición y de los fenómenos culturales, que se transmiten de acuerdo con una dinámica que sobrepasa a la conciencia individual. Pero eso, una vez más, no hace sino poner de manifiesto el momento de alteridad que parece consustancial a la realidad también a la que conforma la esfera sociocultural-, respecto de la cual cada conciencia ha de tomar posición para hacerla suya, lo que en el lenguaje de Husserl quiere decir que los fenómenos de la tradición y de la cultura han de ser asimilados por la conciencia, que - de esta forma- establece su sentido, aunque sólo sea en el modo en que se los apropia a partir de la manera en que se le hacen presentes. De otro modo, desaparecería el momento de subjetividad de la cultura y ésta quedaría reducida a una forma de objetividad inerte equiparable a la de los objetos naturales. Otra cuestión es que dichos fenómenos constituyan un mundo común y compartido, lo cual apunta entonces a una conciencia intersubjetiva como correlato de aquéllos; pero esto es otro problema del que luego nos ocuparemos.

Así pues, hay que distinguir entre la actividad pura de la conciencia, o lado noético, y lo mentado en los múltiples niveles de consideración en los que aquélla recala, que es su correlato noemático. El análisis de Husserl sobre los aspectos noéticos y noemáticos de las vivencias se hace particularmente complejo, pero lo que nos interesa destacar aquí es esa bilateralidad irreductible que acompaña siempre a la vida pura de la conciencia, conforme a la cual a todo objeto intencional le corresponde una forma de intencionalidad del ego consistente en una cogitatio. Husserl lo plantea de acuerdo con el siguiente esquema: ego-cogito-cogitatum. Es decir: la actividad del ego consiste en ese cogito o conjunto de cogitationes, a través de las cuales aquél se refiere a los diversos cogitata que conforman el cogitatum. El esquema sería entonces:

$$
\text { ego } \rightarrow \text { cogito (las diversas cogitationes) } \rightarrow \text { cogitatum (los diversos cogitata) }
$$


La bilateralidad mencionada arriba se refiere a esos dos aspectos que ineludiblemente ha de tener en cuenta el análisis fenomenológico: el del objeto intencional (cogitatum) y el de los modos de conciencia conforme a los cuales aquél es considerado (los que constituyen el cogito). Este desdoblamiento es ineludible, de tal manera que todo el campo de la experiencia se nos presenta para el análisis con esa doble dimensión. Y a partir de ahí Husserl entiende que el hilo conductor trascendental para el descubrimiento de los múltiples tipos de cogitationes o modos posibles de conciencia (que son tipos particulares de intencionalidad) viene dado por el objeto intencional, que está del lado del cogitatum. Husserl parece renovar así lo que Kant presenta como deducción trascendental de las categorías, mediante la cual, a partir de los diversos modos en que el objeto está pensado en el juicio, retrocedemos hasta las formas puras de pensar el objeto en general. Pues es a partir del objeto dado a la conciencia trascendental como se hace posible que la reflexión pueda retroceder al correspondiente modo de conciencia y descubrir así los tipos de intencionalidad que corresponden a los objetos en cuestión. La tarea de la teoría trascendental consiste justamente en explicitar sistemáticamente esos tipos estructurales, formas o funciones noéticas a través de los cuales la intencionalidad constituye trascendentalmente el objeto ${ }^{47}$.

Se pone así de manifiesto una vez más la influencia de Kant, respecto de la cual conviene hacer algunas observaciones. Aunque generalmente se suele hablar de una renovación del enfoque cartesiano por parte de Husserl, no es menos importante en su pensamiento la herencia de Kant. Es verdad que sigue la estela cartesiana cuando recurre a la intuición intelectual y al valor normativo de la evidencia; y, sobre todo, cuando vuelve al ego cogito como principio fundamental. Pero el pensamiento de Husserl es sobre todo heredero del criticismo kantiano, y sus recursos cartesianos en ningún caso significan un retorno a un punto de vista precrítico. Pues toda la reflexión fenomenológica es un esfuerzo sostenido que, en la línea del giro copernicano de Kant, trata de explicar el sentido de los fenómenos mediante la identificación de los modos de la conciencia que intervienen en la determinación del objeto intencional de que se trate. Por eso, como ya se ha dicho, a la hora de analizar el campo trascendental de la

47 Meditaciones cartesianas, $2^{a}$ Meditación, § 21, pp. 67-69. Vid. también Wilhelm Szilasi, Introducción a la fenomenología de Husserl, Buenos Aires, Amorrortu, 1973, p. 136. Traducción de Ricardo Maliandi. 
experiencia, Husserl ve en el objeto intencional el hilo conductor para el descubrimiento de los múltiples tipos de cogitationes o modos noéticos posibles en que tiene lugar la experiencia de los objetos. Asimismo, Husserl toma de Kant la noción de la síntesis, de la cual hace un uso renovado tanto para explicar el modo de proceder de la conciencia en su determinación de los objetos, como en su concepción de una unidad sintética del yo.

\section{CONSTITUCIÓN DEL SENTIDO Y SÍNTESIS DEL OBJETO}

Husserl entiende la intencionalidad como actividad constituyente de acuerdo con su teoría de la constitución trascendental del objeto en general ${ }^{48}$, pero dicha constitución del objeto no quiere decir creación o invención del mismo, ya que en la cosa hay siempre un momento de trascendencia. Pero esta última no indica otra cosa - según hemos visto- sino un modo de aparecer a la conciencia según un sentido que ha de originarse inmanentemente en ella. Entonces, si se alcanzara el punto final - aunque inalcanzable de facto- hacia el que tiende el proceso de apropiación de la conciencia, el ser del objeto sería finalmente su sentido constituido por ella. Esta constitución del ser del objeto que nos revela su sentido no se hará presente de manera inmediata, sino que remitirá al conjunto total de las experiencias posibles y concordantes que caben de él. $Y$ en la medida en que el "horizonte intencional" de una vivencia no contiene sólo lo directa o explícitamente mentado en la experiencia en cuestión, sino además todo el amplio campo de lo "co-mentado" en las múltiples formas de implicaciones de la misma (incluyendo las protenciones, o expectativas asociadas a modo de anticipación a dicha vivencia; las retenciones, referidas a otras vivencias similares del pasado que se recuerda; el carácter multiforme de sus modos de aparición; etc.), resulta que el sentido objetivo nunca llega a darse del todo de modo acabado, sino que permanece en ese horizonte intencional. Pues el análisis intencional muestra que en todo cogito lo mentado por la conciencia es siempre más que lo que en cada momento se halla como actualmente presente en ella: hay un horizonte de potencialidades susceptible de sucesivas explicitaciones, elucidaciones, aclaraciones. Y este mentar más allá de sí (del objeto

\footnotetext{
${ }^{48}$ Meditaciones cartesianas, Meditación cuarta, § 41, p. 114.
} 
mentado directamente) que yace en toda conciencia tiene que ser considerado como un carácter esencial de ella ${ }^{49}$. De tal manera que el sentido no es representable jamás como algo dado de modo acabado. Y la tarea de la fenomenología consiste entonces en el trabajo interminable de describir y analizar explícitamente todo ese campo de implicaciones predelineadas en el horizonte intencional.

A propósito del concepto de constitución, tan fundamental en Husserl, es interesante la interpretación propuesta por Paul Ricoeur ${ }^{50}$, con la que trata de alejarse del idealismo subjetivo en la dirección de una visión hermenéutica. Ricoeur entiende la constitución como explicitación del sentido y no como creación de éste. Y ciertamente esta interpretación no es ajena a la concepción de Husserl, pues en definitiva el mundo de la vida en el que siempre ya nos hallamos se encuentra con la existencia fáctica de fenómenos dados a la conciencia natural, tan sólo a partir de la cual se inicia la tarea fenomenológicatrascendental de explicitar y mostrar síntesis de sentido en la constitución de los objetos de la experiencia, en un procedimiento retroactivo que busca retrospectivamente hacer explícitos los momentos en que aquellos sentidos fueron constituidos. Sin embargo, pensamos que la constitución del sentido, como ocurre siempre en Husserl, encierra tanto el momento de hacer explícito lo que está ya siempre incorporado en nuestras interpretaciones en cuanto "aquello con lo que ya contábamos" y ahora ponemos en claro - que es el aspecto resaltado por Ricoeur-, como también el momento productivo a través del cual el sentido se revela originado por un ego que, por decirlo así, se anticipa a sí mismo en el encuentro con dichas interpretaciones redescubriéndolas como resultado de su propia actividad intencional.

El comentario anterior a propósito del concepto de constitución nos conduce a la noción de síntesis - que es un modo de constitución-, noción fundamental en la fenomenología trascendental para explicar la unidad del objeto $y$, más allá, la unidad misma de la conciencia en cuanto ego. Husserl explica que se trata en realidad de la forma originaria con que opera la conciencia, en cuanto ésta unifica diversas vivencias en la experiencia de un objeto. Sin embargo, en la génesis constitutiva de éste, distingue dos formas diferentes: una síntesis

\footnotetext{
${ }^{49}$ Ibidem, Meditación segunda, § 16, p. 53.

50 Vid. Paul Ricoeur, "Hegel et Husserl sur I'intersubjectivité", en AA.VV., Phénomenologies hégelienne et husserlienne. Les classes sociales selon Marx, Paris, C.N.R.S., 1981, pp. 5-17.
} 
activa y una síntesis pasiva. La primera se refiere a la actividad constituyente mediante la cual el yo, por medio de actos específicos, produce el sentido de un nuevo objeto sobre la base de objetos ya dados. Husserl señala que la razón práctica en su más amplio sentido -que incluye a la razón lógica- procede mediante esta actividad constituyente del yo. Así, por ejemplo, el número es el objeto producido que resulta de la síntesis del acto sucesivo de numerar; o el predicado es resultado del acto de predicar $^{51}$. Pero en el caso de los objetos físicos, la constitución del objeto de que se trate en cada caso se produce mediante la síntesis en una unidad de los múltiples y multiformes modos en que dicho objeto aparece en la vida fluyente y continua de la conciencia ${ }^{52}$. De tal manera que esos modos suyos de aparición en el tiempo no son una mera sucesión inconexa de vivencias, sino que transcurren, por el contrario, en la unidad de una síntesis, gracias a la cual se adquiere la conciencia de una y la misma cosa como la que aparece en ellos ${ }^{53}$. Ahora bien, aunque toda síntesis tiene el significado de una efectuación, esa apelación a la objetividad previamente dada para producir activamente la síntesis de un nuevo objeto quiere decir que se recurre a lo ya presupuesto. Presupone, por ejemplo, las diversas caras con antelación al cubo como unidad sintética de ellas; o presupone las diferentes perspectivas y modos de darse un cubo para poder captarlo como la unidad de una forma, un color y un material concretos; o diferentes cubos para poder elaborar sintéticamente la noción ideal de cubo; etc. Por eso, Husserl habla de una síntesis pasiva para referirse a esa presuposición, a lo siempre ya dado como objeto "a partir de lo cual" se constituye todo nuevo objeto. Es decir, toda construcción activa del sentido de un objeto pre-supone una pasividad pre-donante, de manera tal que siguiendo aquella actividad nos topamos con la constitución por la síntesis pasiva, o sea, con que es en relación con los objetos pre-dados como se efectúa - por asociación- la síntesis de los nuevos ${ }^{54}$. Esto remite a una consideración psicológica acerca de los momentos del pasado (Husserl hace referencia incluso a la infancia) en que empíricamente se alcanzó en su origen la experiencia primera de los objetos que ahora se presupone, pero desde el punto de vista fenomenológico significa que, en nuestra vida, las

\footnotetext{
${ }^{51}$ Meditaciones cartesianas, Meditación cuarta, § 38, pp. 103ss.

52 Ibidem, Meditación segunda, § 17, pp. 54ss.

${ }_{53}$ Por eso, la forma fundamental de la síntesis es la identificación. Vid. Ibidem, Meditación segunda, $\S 17$, p. 55, y $\S 18$, pp. 57 ss.

54 Ibidem, Meditación cuarta, § 38, p. 104.
} 
actividades espirituales o actualizadoras, es decir, las que -en este casoefectúan un acto creativo de conocimiento, se desarrollan siempre a partir de lo que la vida nos presenta como algo ya concluido, como mera cosa con la que topamos y nos es dada sin más. Esa pasividad alude a una "materia", como lo pre-dado, en contraposición al "espíritu", que es el lado activo de la captación $^{55}$. Y mientras esas actividades espirituales efectúan sus síntesis activas sigue estando operante la síntesis pasiva que les suministra la "materia" a todas ellas. Eso quiere decir que la cosa pre-dada sigue apareciendo como unidad en la intuición, aunque sobre ésta pueda hacerse igualmente un análisis que distinga partes o notas. Ahora bien, esa unidad no deja de ser la unidad de una historia de experiencias que han aparecido en el tiempo y que ha quedado contraída, por decirlo así, en la fijeza del nuevo objeto que ahora experimento. Pero el ego puede reflexionar sobre esa historia y tratar de captar los fenómenos actuales como formaciones subsecuentes a otras formaciones que los preceden, según leyes de formación pasiva de síntesis siempre nuevas, como configuraciones persistentes en una habitualidad que les es propia. ${ }^{56}$ Eso significa que todo lo conocido remite a un originario llegar a conocer. Por lo tanto, esa "materia"57 siempre dada en la captación de lo nuevo nos remite a su vez a algún momento originario anterior a partir del cual tuvo que poder aparecer como tal. Por otro lado, gracias a esa síntesis pasiva, el yo tiene siempre un contorno de objetos como lo que está ya siempre ahí, y a ella se debe también el hecho de que todo lo que me afecta sea apercibido como objeto ${ }^{58}$.

Ahora bien, la síntesis pasiva implica que en la configuración de un nuevo sentido hay un momento de pasividad consistente en que lo nuevo queda necesariamente asociado con lo ya objetivamente dado de antemano. Por eso dice Husserl que la asociación es el principio universal de la génesis pasiva, pues ésta tiene una estructura asociativa ${ }^{59}$. Pero no se trata aquí de las leyes de asociación del empirismo clásico, que Husserl considera una deformación naturalista de algo que la fenomenología descubre en su raíz como algo más pro-

${ }^{55}$ Idem.

56 Ibidem, p. 105.

57 Aquí el término "materia" no se refiere sólo a los datos hyléticos, sino a lo ya dado y conocido como base para la síntesis activa, y eso ya conocido tiene también su forma. Pero si nos remontamos hacia atrás nos toparíamos necesariamente con los datos hyléticos como lo primeramente dado.

58 Ibidem, p. 106.

59 Una forma originaria de asociación en la síntesis pasiva es la que denomina Husserl "apareamiento" o "parificación" (Paarung), concepto importante en la fundación de la intersubjetividad, como luego veremos. 
fundo. Por el contrario, la estructura asociativa de la síntesis pasiva expresa la propia legalidad rectora de la intencionalidad constituyente del ego, la cual no hace sino expresar la síntesis de la conciencia del tiempo en la unidad del ego como tal. No se trata, por lo tanto, de leyes empíricas que rijan las relaciones entre los datos psíquicos. Por el contrario, la asociación

[...] expresa la legalidad intencional esencial de la constitución del ego puro, el reino a priori innato, sin el cual, por tanto, no es concebible un ego como tal. Tan sólo gracias a la fenomenología de la génesis el ego se hace comprensible como un nexo infinito de efectuaciones sintéticamente congruentes ligado en la unidad de una génesis universal. [Pero esto debe adaptarse] a la forma universal y persistente de la temporalidad, porque esta misma se edifica en una constante génesis pasiva y completamente universal $[\ldots] .^{60}$

\section{EL YO COMO FORMA DE LA SÍNTESIS UNIVERSAL:}

LA CONTINUA CONCIENCIA DEL TIEMPO INMANENTE Y LA UNIDAD SINTÉTICA DE LAS VIVENCIAS

En el esquema examinado anteriormente el ego aparece con antelación no sólo al cogitatum, sino también a aquello que es su propia actividad, el cogito; lo cual quiere decir que hay un yo que es anterior a sus pensamientos, aunque no nos podamos acercar a él más que a través de éstos, que fluyen de él. Esto nos permite hacer una observación terminológica pero que tiene un alcance ontológico. Nos referimos al uso de los términos "conciencia" y "yo", que hasta ahora venimos usando como equivalentes. En rigor, la vida de la conciencia se extiende más allá del yo, como se muestra en el esquema tripartito ego-cogitocogitatum, al que antes nos referíamos para distinguir en las vivencias los aspectos noéticos de los noemáticos. Pero también veíamos cómo ese esquema apunta a un polo de unificación de todas las vivencias en el yo o ego. De ese modo indica Husserl que, a pesar de la multiplicidad de vivencias que fluyen en la conciencia y a pesar de la compleja variedad de elementos noéticos y noemáticos que el análisis puede discriminar en ella, la entera vida de la conciencia debe entenderse en su totalidad como un principio unitario. Parece que Husserl trata de asegurar así la precedencia última del ego en cuanto unidad de la conciencia que en cierto modo antecede a sus modos de referirse intencio-

\footnotetext{
${ }^{60}$ Meditaciones cartesianas, Meditación cuarta, § 39, pp. 107s.
} 
nalmente a los objetos. Sin embargo, se trata de una unidad sintética, es decir, de una unidad que, aunque siempre está presupuesta en relación con las nuevas experiencias, debe entenderse a la vez como el resultado de una unificación o síntesis universal de la infinidad de vivencias que fluyen en la continuidad del tiempo.

Para aclarar lo anterior, y volviendo a la constitución del objeto, digamos que éste se me da como la unidad sintética de sus modos de aparición, todos los cuales mantienen un nexo en la continuidad del tiempo. Pero, por otro lado, la unidad de la conciencia, que realiza en sí de modo permanente ese nexo continuo de las vivencias, ha de preceder necesariamente a la síntesis de los objetos. Así pues, al igual que antes hizo Kant, también Husserl funda la unidad del objeto en la unidad sintética de la conciencia, pues se trata de "[...] un enlace de la conciencia única en la que se constituye la unidad de una objetividad intencional como la misma en los modos múltiples de aparición" ${ }^{61}$. De modo que:

El objeto de la conciencia en su identidad consigo mismo, durante el vivenciar fluyente, no viene a la conciencia desde afuera, sino que yace implicado en ella como sentido, esto es, como efectuación intencional de la síntesis de la conciencia. ${ }^{62}$

Pero aunque la identidad unitaria del objeto se funde en la unidad de la conciencia, el planteamiento de Husserl difiere del enfoque kantiano en puntos fundamentales. Una diferencia básica se encuentra en que para Kant la síntesis de los datos sensoriales en la unidad del objeto presupone la distinción entre forma y contenido en términos tales que la actividad sintética se entiende como la de unas formas que se aplican al contenido sensible previamente dado, lo cual le permite a Kant entender el yo como un principio lógico atemporal y siempre presupuesto en cuanto unidad de las formas lógico-trascendentales. En Husserl, en cambio, semejante distinción no se mantiene en esos términos, pues la síntesis del objeto se entiende como la unidad de todos sus modos de aparición en el tiempo, pero de tal manera que en cada una de sus apariciones el nóema u objeto intencional no es sólo un contenido o sólo una forma, ya que ambos aspectos son correlato de configuraciones noéticas con las cuales la actividad de la conciencia los determina intencionalmente. Por lo tanto, Husserl no concibe la unidad sintética de la conciencia como un mero presupuesto lógi-

${ }^{61}$ Ibidem, Meditación segunda, § 18, p. 58.
${ }^{62}$ Idem. 
co de carácter intemporal. Por el contrario, el ego trascendental de Husserl, en cuanto unidad de la conciencia - que hace posible la unidad del objeto- se presenta como la continua conciencia del tiempo inmanente, que es la forma fundamental de la síntesis universal, es decir, no la de este o aquel objeto, sino la síntesis de la vida entera de la conciencia: "Toda vivencia particular concebible es tan sólo un destacarse en una conciencia total ya siempre presupuesta como unitaria"63.

Ahora bien, la unidad sintética de la vida entera de la conciencia, concebida como continua conciencia del tiempo inmanente que todo lo abarca, supone la noción del tiempo fenomenológico, que ha de distinguirse del tiempo cósmico o tiempo objetivo: como leemos en Ideas, el tiempo fenomenológico es la forma unitaria de todas las vivencias que, por ello mismo, entran en una única corriente de la conciencia ${ }^{64}$. Es esta unidad del tiempo continuo e inmanente a la conciencia lo que funda la unidad sintética de ésta como un yo temporalizado, siempre presupuesto en sus vivencias particulares:

La temporalidad no sólo designa algo universalmente inherente a cada vivencia aislada, sino una forma necesaria de unión de unas vivencias con otras. Toda vivencia real (logramos esta evidencia sobre la base de la clara intuición de la realidad de una vivencia) es necesariamente una vivencia que dura; mediante esta duración se inserta en un continuo sin término de duraciones - un continuo lleno. Toda vivencia tiene necesariamente un horizonte de tiempo lleno e infinito por todos lados. Esto quiere decir al mismo tiempo: toda vivencia pertenece a una "corriente de vivencias" infinita. ${ }^{65}$

También en Ideas, unas páginas más adelante, comenta Husserl que esa corriente de vivencias - que sería una unidad infinita - tiene una forma unitaria - la temporalidad- que abarca necesariamente todas las vivencias de un yo puro $^{66}$. La unidad del yo puro se captaría, por lo tanto, como la unidad del tiempo fenomenológico que define la forma de todas las vivencias -en cuanto duran- y de su unión continua en una única corriente de la conciencia. De tal manera que el ego no sólo se intuye como vida que fluye en tanto continuo de vivencias intencionales, sino que se capta también como siendo uno y el mismo, como polo idéntico que abraza todas las cogitationes particulares ${ }^{67}$, incluyendo las referidas al pasado y al futuro hacia las que se extiende, y que el yo

\footnotetext{
63 Ibidem, p. 59.

${ }^{64}$ Ideas I, § 81, p. 191.

${ }^{65}$ Ibidem, p. 193.

${ }^{66}$ Ibidem, \& 82, p. 195.

67 Meditaciones cartesianas, Meditación cuarta, § 31, pp. $88 \mathrm{~s}$.
} 
conecta con su continuo presente viviente en cuanto retenciones y protenciones: el yo se capta distendido temporalmente, recordando(se) y proyectando(se). Así, el pasado se constituye a partir del ahora de mis recuerdos, del mismo modo que en el continuo flujo de mis vivencias se proyecta el futuro.

Repitiendo a su manera - una vez más- el planteamiento kantiano, nos dice Husserl que esa conciencia unitaria y total acompaña a todas sus vivencias, sólo que nos presenta esa apercepción como la intuición de la vida total y fluyente de la conciencia, siempre presupuesta y respecto de la cual se destaca una u otra vivencia en particular. Pero a diferencia de Kant no se trata ya de la unidad de la conciencia comprendida como sujeto lógico antepuesto a sus funciones trascendentales, sino de un yo temporalizado que se intuye a sí mismo como unidad sintética en cuanto conciencia continua del tiempo en el que se distiende. Por lo tanto, Husserl va más allá de Kant también en este sentido, en cuanto admite - siguiendo la línea de Fichte- el conocimiento intuitivo de la identidad del yo. Ahora bien, en su interpretación de la relación entre el yo y el mundo, Husserl trata de evitar la deriva dialéctica - apartándose así del camino fichteano- cuando comprende dicha relación mediante el concepto de la intencionalidad con su doble sentido, que alude a una conciencia-de referida a un objeto que a su vez es objeto-de aquélla.

En cualquier caso, nos encontramos aquí con un momento de máxima tensión del pensamiento: el sujeto trascendental de Husserl es un sujeto temporal. ¿Cómo es eso posible? En este caso, la comparación con Kant no nos sirve de ayuda, pues aunque para Kant el tiempo es también una forma del sujeto, lo es en un sentido diferente que nos permite decir que el sujeto trascendental es él mismo atemporal: el tiempo para Kant es una forma del sujeto en cuanto condición trascendental de toda intuición empírica, o sea -como dice Kant- es una intuición pura. Pero el sujeto kantiano no es temporal en el sentido de estar él mismo distendido en el tiempo, pues no puede estar en el tiempo si él es condición del mismo. Pero Husserl empieza por rechazar el dualismo kantiano referido al sujeto empírico y al sujeto trascendental: es un único yo el que pertenece al mundo empírico y a la vez se adelanta al mismo para dar cuenta de su pertenencia a él. Y las experiencias que el sujeto acumula en el tiempo quedan sedimentadas en él y son condición de las nuevas experiencias. De modo que el ego trascendental se anticipa a todas las experiencias, a la vez que él mismo se temporaliza como resultado de las mismas. Su unidad es la de la co- 
rriente unitaria de la conciencia que se intuye como una y la misma en la duración de todas sus vivencias. Pero, ¿cómo puede el sujeto trascendental ser temporal y, por ende, ser a la vez empírico? No sería un yo a priori en el sentido kantiano, porque ese ego trascendental de Husserl no es independiente de toda experiencia, en tanto él mismo es un precipitado de experiencias anteriores que con él han alcanzado una síntesis unitaria. Sin embargo, es a priori en el sentido de preceder a toda nueva experiencia y también en el sentido más general de que no hay experiencia propiamente dicha - al menos en el sentido humano del término- sin un polo subjetivo que sea condición de su posibilidad. Por otro lado, ese yo trascendental, que al mismo tiempo es un sujeto empírico en el sentido señalado, no sería en esos términos un ego puro. No lo sería al menos según el significado que Kant asigna a ese término. $Y$, sin embargo, Husserl habla de un yo puro. A ello nos referiremos después, pero para explicarlo necesitamos antes hacer referencia a la reducción eidética.

Pero, antes de concluir este punto, es interesante llamar la atención sobre la reflexión que Husserl desarrolla en las Meditaciones cartesianas sobre el ego trascendental, considerando sucesivamente diversos aspectos del mismo:

a) En primer lugar, el ego trascendental se presenta como inseparable de sus vivencias, constituyéndose a través de ellas y siendo condición de posibilidad de las nuevas experiencias ${ }^{68}$.

b) Por otro lado, ese yo es captado intuitivamente -según hemos vistocomo polo idéntico de las vivencias ${ }^{69}$.

c) Además, ese yo no es un polo vacío de identidad, sino un "sustrato de habitualidades", de tal manera - señala- que la permanencia del objeto (es decir, su identidad como unidad de una síntesis) en sus diversas apariciones ha de entenderse como el correlato de la habitualidad que se constituye en el yomismo, en tanto éste es la unidad sintética de sus cogitationes ${ }^{70}$.

d) A continuación, se refiere Husserl a la plena concreción del yo trascendental como mónada, es decir, al yo concreto que cada cual es en exclusiva, abstraído de los otros, y que arraiga en "la fluyente multiformidad de su vida intencional" - tan sólo en la cual puede el yo ser concreto. Pues bien, en ese ego monádico, que representa la máxima concreción del yo, tiene que encon-

\footnotetext{
${ }^{68}$ Ibidem, Meditación cuarta, § 30, pp. 87s.

${ }^{69}$ Ibidem, Meditación cuarta, § 31 , pp. 88s.

70 Ibidem, Meditación cuarta, § 32, pp. 89s.
} 
trarse de modo necesario real o potencialmente toda la vida de la conciencia, de tal manera - nos dice Husserl- que la explicitación fenomenológica de ese ego monádico tiene que abarcar todos los problemas constitutivos en general ${ }^{71}$.

e) Finalmente, Husserl distingue el ego puro, que no es el yo trascendental del que venimos hablando, sino el yo trascendental en general, para cuya determinación hemos de servirnos de la reducción eidética ${ }^{72}$.

8. LA INTUICIÓN EIDÉTICA, LA CUESTIÓN DEL EGO PURO Y SU SIGNIFICADO ANTROPOLÓGICO

El recurso a la intuición significa que la identidad del objeto, que se revela - según lo ya comentado- a través de su síntesis, no resulta - como en Kantdel uso de los conceptos puros, sino de la donación de un sentido intuido por el yo para él a través de las vivencias hechas sobre dicho objeto. Reducido a fenómeno trascendental por la conciencia fenomenológica, ésta capta ahora además su esencia mediante esa intuición en lo que Husserl denomina "reducción eidética" de tal fenómeno. Sin embargo, Merleau-Ponty comenta a este respecto que existe un malentendido cuando se habla en Husserl de la búsqueda de las esencias, porque para él, en rigor, toda reducción es, a la par que trascendental, necesariamente eidética, lo cual quiere decir que no podemos someter a la mirada filosófica nuestra percepción del mundo sin pasar del hecho de nuestra existencia a la naturaleza de la misma, la cual tiene necesidad del campo de la idealidad para conocer y conquistar su facticidad ${ }^{73}$. En efecto, la reducción eidética remite el fenómeno a su pura esencia, lo reduce a su eidos, y con ello se completa el proceso que nos aleja críticamente de la actitud natural, porque esta nueva actitud fenomenológica que nos limita a la contemplación de la esencia de los fenómenos entraña una suerte de supresión de lo sensible, de abolición de esa realidad mundana en la que nos desenvolvemos por lo común. Esta reducción practica la epoché en cuanto a la realidad fáctica del objeto en cuestión en busca de su pura idea. Y para efectuar seme-

${ }^{71}$ Ibidem, Meditación cuarta, § 33, pp. 91s.

72 Ibidem, Meditación cuarta, § 34, pp. 92ss.

${ }^{73}$ Maurice Merleau-Ponty, Fenomenología de la percepción, Barcelona, Península, 1975, p. 14. Traducción de Jem Cabanes. 
jante operación el fenomenólogo utiliza el "método de la variación eidética" o de "la libre variación imaginaria". Así, pongamos por caso,

\begin{abstract}
Partiendo del ejemplo de la percepción de esta mesa, variemos el objeto de percepción "mesa" con entera libertad; pero de modo que sigamos teniendo una percepción como percepción de algo [...], manteniendo de modo idéntico tan sólo el aparecer perceptivamente. [Así], absteniéndonos de toda afirmación respecto de su validez de ser, transformamos el factum de esa percepción en una pura posibilidad entre otras puras posibilidades totalmente opcionales [...] Por así decirlo, transferimos la percepción real al reino de las irrealidades [...], que nos procura las posibilidades puras; puras de todo lo que las liga a ese factum y a todo factum en general. [...] El tipo "percepción" así obtenido flota por así decirlo en el aire -en el aire de las puras cosas imaginables. Así, despojado de toda facticidad, se ha convertido en el eidos percepción", cuyo ámbito ideal integran todas las percepciones idealiter posibles [...] Los análisis de la percepción son entonces análisis de esencias. ${ }^{74}$
\end{abstract}

De esa manera, todo factum puede pensarse como mero ejemplo de una posibilidad pura. Pero entonces el correlato de esa variación imaginaria que capta lo universal tiene que ser "una conciencia intuitiva y apodíctica de lo universal"75.

Reducirse a la esencia de las cosas comporta suprimir su consistencia sensible, su peso, su resistencia, su presión, su existencia mundana en definitiva, para retener tan sólo su eidos. Y el significado de esta posibilidad que se le abre al hombre de separar la esencia inteligible de las cosas de aquello que constituye su existencia material sensible, es algo que, desde Platón, no ha dejado de considerarse en la filosofía, sobre todo en la tradición idealista. Husserl la incorpora a su propia reflexión, señalando que la posibilidad de efectuar esa reducción del objeto fenoménico a su pura esencia inteligible indica en el sujeto que la lleva a cabo un poder de despegarse de la realidad fáctica y sensible; pone de manifiesto en el ego trascendental unas fuerzas noéticas que apuntan a objetos inteligibles completamente independientes de toda experiencia; es decir, demuestran la realidad de un yo racional puro.

Insistiendo precisamente en esta consideración de su maestro sobre la intuición eidética, Max Scheler desarrolló el significado antropológico de la capacidad ideatoria que brinda al hombre la posibilidad del conocimiento. Según su concepción ${ }^{76}$, el conocimiento nos permite representarnos el mundo y captar

${ }^{74}$ Meditaciones cartesianas, Meditación cuarta, § 34, pp. 94s.

75 Ibidem, p. 96.

${ }^{76}$ Vid. Max Scheler, El puesto del hombre en el cosmos, Buenos Aires, Losada, 1938, pp. 67ss. Traducción de José Gaos. 
intuitivamente la esencia de las cosas. Pero, a diferencia del acto ideatorio por el que se nos descubre la esencia de las cosas que conocemos, su existencia se nos hace patente por una vía muy distinta. En efecto, la existencia de las cosas se nos revela en una experiencia más primaria, a saber: en la vivencia de la resistencia que ofrece el mundo ante nuestros impulsos. Esta vivencia precede a toda conciencia y no es exclusiva del hombre. $\mathrm{Y}$ además no puede llamarse en rigor conocimiento, porque no hay conciencia ni representación alguna en ella: no es un acto del espíritu - de acuerdo con la terminología de Scheler-, sino la vivencia de que hay una realidad que se nos hace patente en la resistencia que encuentra nuestro impulso vital. Pues bien, partiendo de esa base, y yendo más allá, idear el mundo sería, por ello mismo, "desrealizarlo", es decir, abolir el momento de la realidad fáctica misma (haciendo epoché -diríamos con Husserl- de su existencia, que significa resistencia, presión, etc.), y, según eso, el conocimiento mismo, en cuanto ideación de las esencias al margen de toda existencia, es un acto ascético que comporta la anulación de ese impulso vital. La conclusión de Scheler es que el hombre no sólo es un ser viviente, sino también el yo que es capaz de un acto contrario a la lógica de la vida, porque puede adoptar una actitud ascética frente a ésta. Esta posición la desarrolla Scheler en el contexto de la discusión postnietscheana sobre el espíritu y la vida $-\mathrm{y}$ en un sentido dualista opuesto al planteamiento del propio Nietzsche-, y conduce desde luego a un punto que rebasa los límites entre los que se desenvuelve la discusión de Husserl sobre el sujeto. Pero se orienta claramente de acuerdo con la concepción de éste sobre la reducción eidética y su significado en el plano antropológico.

Ahora bien, ese yo capaz de idear el mundo separándolo de su existencia fáctica se concibe como actividad que se adelanta a toda realidad ya dada. Por eso, en rigor, mi yo no se puede identificar con mi cuerpo. Sin duda soy un cuerpo que centraliza toda mi experiencia sensible. Pero ese cuerpo que soy se me presenta como una cierta objetivación de mi yo. Del mismo modo que puedo poner en práctica una iniciativa que se distingue y se adelanta a su posible objetivación posterior en hábitos, rutinas, o automatismos en general, en los que se pierde el carácter genuino de mi acción primera, también mi cuerpo es en cierto modo - aparte de la naturaleza que me recorre por dentro y por fuera- un precipitado de impulsos y acciones que cristalizan como el pasado de mi yo. Por otro lado, puedo experimentar mi propia corporeidad mediante sensa- 
ciones de diversos tipos que me la presentan como algo que en cierto modo no puedo separar de mí mismo. Sin embargo, esas sensaciones que me delatan como el cuerpo que soy me colocan ante mi propia pasividad. Por eso Husserl distingue de ellas la actividad originaria del yo, que por un lado parece adelantarse a toda percepción pasiva de nosotros mismos, pero que también procede a partir de ésta mediante un acto reflexivo posterior que vuelve conscientemente sobre sí y me permite diferenciarme de ese cuerpo para designarme como un yo. El yo queda en cierto modo corporeizado cuando él mismo se convierte en objeto de su propia experiencia, y, por ello mismo, en algo ya dado de nosotros mismos, cuya expresión más inmediata es mi cuerpo. Pero distinto siempre de este yo encontrado es el yo que busca en cuanto actividad autoconsciente que se sustrae a toda objetivación o que, al menos, renace una y otra vez a partir de ésta. Así pues, en este segundo sentido, mi cuerpo es mío, pero no soy yo. $Y$ el momento irreductible de la subjetividad humana consiste en ese modo de resurgir del yo, que siempre de nuevo se diferencia de lo que ya era en cuanto yo cosificado u objetivado como cuerpo. La grandeza de la filosofía de Husserl -nos parece- se halla justamente en el reconocimiento de ese momento de irreductible subjetividad que acompaña a la experiencia humana. Aunque, según nuestra interpretación, su proyecto filosófico se desenvuelve de acuerdo con la tradición idealista, que lleva a cabo una hipóstasis del yo que no consigue finalmente justificar.

Ahora bien, antes hemos hablado de un yo racional puro, que por definición -si somos consecuentes en el uso de las palabras- sería enteramente independiente de cualquier experiencia. Recogemos aquí, por lo tanto, el problema antes apuntado acerca de un yo trascendental que, a diferencia de lo antes señalado sobre su carácter temporal y su autoconstitución a través de sus experiencias, ahora se trata de un sujeto puro. De acuerdo con este término tomado de $\mathrm{Kant}^{77}$, tal sujeto no sólo sería a priori, en el sentido ya explicado de ser condición de las nuevas experiencias -aunque, según Husserl, sí se habría enriquecido con las experiencias anteriores depositadas en él- sino que sería además puro y, por lo tanto, independiente de toda experiencia. Ese ego puro

\footnotetext{
77 Recuérdese que, de acuerdo con Kant, "puro" es aquel conocimiento que no sólo es a priori, sino que además no ha recibido ningún añadido empírico. Parece que Husserl tiene en cuenta este uso de Kant, al cual él añade en ocasiones otro cuando habla, por ejemplo, de fenómeno puro o de la pura corriente de las vivencias. En este caso, "puro" se usa con el significado del ser que resulta después de haber suprimido la actitud natural mediante la reducción trascendental.
} 
invocado por Husserl es, por lo tanto, un yo desencarnado, un yo que en cierto modo se anticipa radicalmente al mundo en su totalidad en cuanto es condición de todo cuanto en éste pueda presentarse con sentido. Sólo una noción semejante del yo le parece a Husserl que puede dar cuenta del significado racional del conocimiento, pues conocer implica rebasar el plano de la mera facticidad para alcanzar las ideas mediante las que se comprenden los hechos; significa, por lo tanto, captar la esencia de los fenómenos - reducción eidética- y no sólo reducirlos a su pura inmanencia en la conciencia - reducción trascendental. Semejante actividad ideatoria no es posible para un yo fáctico, sino tan sólo para un sujeto que se adelanta radicalmente a su propio ser mundano.

¿Pero cómo se determina ese ego trascendental puro? ¿Y cómo accedemos a ese yo esencial, cuyo ser inteligible -el eidos "ego" - está separado de toda existencia fáctica? Según Husserl, no se trata de una noción extraída por abstracción de los diversos yoes, que retuviera lo que todos tienen en común, pues en tal caso no habríamos superado el nivel de lo fáctico: una esencia no es una suma de hechos. Por el contrario, ese ego esencial se alcanzaría mediante la "variación de posibilidad" de mi ego fáctico, según el método antes mencionado de la variación eidética. Es decir, a partir de mi yo particular y sin necesidad de plantear siquiera la cuestión de los otros yoes, puedo acceder a "un ego en general", de modo que:

Aquí la extensión del eidos "ego" está determinada por la autovariación de mi ego. Sólo yo mismo me imagino como siendo otro, pero no imagino los otros. Así, pues, la ciencia de las posibilidades puras precede "en sí" a la de las realidades y únicamente ella posibilita a ésta como ciencia. ${ }^{78}$

Por lo tanto, el ego puro o la esencia del yo se determina como un "ego trascendental en general", que Husserl distingue del "ego trascendental empírico-fáctico"79, del cual ya habíamos hablado antes. Ese ego puro, sin embargo, no es ajeno al yo individual, sino que está presente en él y en todo ego fáctico, del mismo modo que la esencia no es ajena a los fenómenos en que está presente. Ese yo puro es el yo racional que todo individuo es capaz de ser cuando se determina conforme a las ideas. A la fenomenología le correspondería entonces la tarea de establecer cuáles son las legalidades conforme a las cuales ese ego puro constituye intencionalmente sus objetos, cuáles son las fuerzas noéti-

\footnotetext{
${ }_{78}$ Max Scheler, El puesto del hombre en el cosmos, p. 97.

${ }^{79}$ Ibidem, p. 96.
} 
cas de máxima generalidad que definen su actividad. Hacia eso precisamente se encaminaría una egología pura. Por eso, escribe Husserl:

\begin{abstract}
La fenomenología [...] es un idealismo que no consiste más que en la autoexplicitación de mi ego como sujeto de todo posible conocimiento, llevada a cabo de modo consecuente en la forma de una ciencia egológica sistemática, y esto con respecto al sentido de todo lo que es, que debe poder tener justamente un sentido para mí, el ego. [...] Es la explicitación del sentido [...] de todo tipo de ser que yo, el ego, sea capaz de concebir, especialmente del sentido de la trascendencia de la naturaleza, de la cultura, del mundo en general. ${ }^{80}$
\end{abstract}

Parece, por lo tanto, que con Husserl se renueva esa vieja tendencia moderna que concede un privilegio a la relación de conocimiento cuando se trata de entender la relación del yo con las cosas y consigo mismo. El primado del yo para él significa que éste nunca es un principio derivado, sino que se encuentra siempre ya constituido con ocasión de cada nueva experiencia, por mucho que ésta pueda luego redefinirlo como ego fáctico (el yo puro sería, en cambio, independiente de toda experiencia). Sin embargo, surge la duda de si acaso, por esta vía, el idealismo de Husserl no se oculta a sí mismo la vivencia del espesor del mundo y el peso de su opacidad, que se nos impone sin remitirnos a ninguna operación previa del yo; si no nos escamotea el sentido sorprendente del azar, al cual nunca nos podemos anticipar; si no nos hurta el significado de lo accidental cuando apela a un yo cuya actividad parece ir siempre por delante. Pues, finalmente, para Husserl, sólo la subjetividad trascendental tiene el carácter de lo absoluto, sólo ese ego es "irrelativo", ya que el mundo y sus objetos, aunque se admitan como reales, estarían marcados por su esencial relatividad al sujeto trascendental.

\title{
9. EL YO DE LOS OTROS Y EL PROBLEMA DE LA INTERSUBJETIVIDAD
}

Según hemos visto, el yo trascendental de Husserl existe como un yo individual. Incluso el yo racional o puro ha de entenderse como el ego esencial que nos da la idea de lo que básicamente todo sujeto existente es. Por eso, Husserl

\footnotetext{
${ }^{80}$ Ibidem, Meditación cuarta, § 41, pp. 113s.
} 
dice que en su máxima concreción ese sujeto existe como yo monádico ${ }^{81}$ con su propio mundo vital (Lebenswelt), en el cual tiene que encontrarse el momento fundacional de todo sentido. A partir de ahí, a la fenomenología se le plantea la dificultad de explicar cómo se concilia esta última afirmación con la existencia indudable de un mundo objetivo y común de significados que se imponen al individuo. La discusión de este problema conduce a la cuestión de la intersubjetividad y, en definitiva, a la que se refiere a la relación con los otros. Pero esto último, a su vez, remite a la pregunta acerca de cómo se presenta el prójimo en la esfera de mi conciencia.

En cualquier caso, la cuestión de la intersubjetividad, expresada en abstracto, se refiere a ese tipo peculiar de experiencia que se da en la relación entre diversos sujetos. Pero hay que decir, en contra de algunas interpretaciones, que lo intersubjetivo no es sinónimo de lo social, pues lo intersubjetivo hace referencia sin más a la relación entre los sujetos, cada uno de los cuales comparte en cierta medida las experiencias del otro, mientras que lo social alude además a una cierta realidad objetiva que media en la relación entre ellos y que tiene entidad propia, como pueden ser los usos o las normas. Ortega lo explica brillantemente cuando señala el sentido impersonal de lo que es propiamente social: así -nos dice-, el guardia que hace un gesto al peatón para que se detenga no está manteniendo con éste un trato personal, sino que actúa como agente de la autoridad; ni él ni el peatón aparecen en esa relación propiamente como personas, sino encarnando símbolos cuyo significado está cifrado en los códigos sociales, como - por ejemplo- el de la circulación. La "socialidad" existe de ese modo: como algo impersonal que en algún momento originario pudo tener el carácter de la intersubjetividad, pero que se ha endurecido en una forma objetiva de tipo simbólico que se intercala en la relación entre los sujetos. Por eso dice Ortega que lo social es lo humano despersonalizado o deshumanizado, o también lo humano sin el hombre ${ }^{82}$, aunque hay que decir que esta última fórmula encierra un sentido peyorativo que apunta -como también pasa en el caso de Heidegger - a una visión recelosa de la sociedad, especialmente la moderna. En cualquier caso, digamos en resumen que lo social encierra un mo-

${ }^{81}$ A este respecto, conviene precisar que así como la distinción kantiana entre el sujeto trascendental y el sujeto empírico es al mismo tiempo la distinción entre un sujeto transindividual y un yo individual, en Husserl, en cambio, según hemos visto, no se mantiene esta dicotomía. pp. 143 ss.

82 Vid. El hombre y la gente, cap. VIII: "De pronto, aparece la gente", Madrid, Espasa-Calpe, 1972, 
mento de intersubjetividad, al cual le añade además un momento de objetividad que contribuye a dar sentido a la relación entre los sujetos.

Y precisamente la concepción de Husserl se sitúa en el límite de esta distinción, pues su proyecto filosófico, en este punto, consiste justamente en el intento de reducir siempre el sentido de toda realidad social objetiva a la conciencia intersubjetiva que le sirve de base, convirtiéndose de este modo la intersubjetividad en un principio trascendental, tan sólo a partir del cual adquirirían su sentido los fenómenos sociales. Y convirtiéndose además en un principio crítico, por cuanto supone el rechazo de toda tentación de hipostasiar o cosificar las relaciones sociales. Paul Ricoeur comenta a este respecto que la sociología comprensiva de Max Weber puede entenderse como el desarrollo sociológico de esta idea de Husserl, que reacciona en contra de una fenomenología del espíritu de tipo hegeliano mediante una fenomenología de la intersubjetividad: el concepto de la analogía del ego (es decir, la comprensión del otro como un alter ego en analogía con mi propio yo), considerado como el trascendental de todas las relaciones intersubjetivas, permitiría combatir la tendencia a hipostasiar las entidades colectivas mediante la voluntad tenaz de reducirlas siempre a una red de interacción. La teoría de los tipos ideales de Weber podría entenderse entonces como una aplicación empírica de esta concepción de Husserl, que sustituye el espíritu objetivo hegeliano por la intersubjetividad ${ }^{83}$. Y de tal modo, además, que para Husserl la intersubjetividad no es una relación entre los sujetos sin más, sino un modo de ser fundamental de la conciencia: la conciencia es intersubjetiva y se encuentra fácticamente siempre en relación con los otros.

En todo caso, la interpretación de la realidad social objetiva a partir de la intersubjetividad que le sirve de base, es coherente con todo el pensamiento de Husserl, para quien no hay objeto sin una conciencia a la que aparece y en la que se origina un sentido para el mismo. En este caso, la realidad social y cultural constituye un tipo de objetividad que tiene como condición de posibilidad "la intersubjetividad monadológica", o sea, la conciencia monádica intersubjetiva, a cuyo ser trascendental se trata ahora de reducir aquella realidad. Pero si la intersubjetividad es una forma de conciencia, y ésta "en su máxima concreción" es un yo monádico, habrá que buscar en éste la fuente de todo sentido, incluyendo la experiencia del yo extraño, la cual ha de poder ser reducida, me-

${ }^{83}$ Vid. Paul Ricoeur, op. cit., pp. 11ss. 
diante una "apercepción analógica", a la esfera exclusiva del propio yo. Éste es el programa que se plantea Husserl en la quinta y última de sus Meditaciones cartesianas.

Pero, desde nuestro punto de vista, lo que está aquí en cuestión, en primer lugar, es la posibilidad misma de considerar la conciencia intersubjetiva con antelación a la objetividad social y natural de la cual depende. Semejante pretensión presupone una visión abstracta del sujeto -aun cuando Husserl reconozca que siempre se encuentra de facto implicado con otros sujetos-, porque parte del inaceptable supuesto de que la relación entre los sujetos se puede considerar separándola del momento de objetividad que se intercala entre ellos y determina de antemano la concreta forma social que necesariamente adopta toda relación interhumana. No hay una relación entre sujetos puros, separados de su concreta configuración en un lugar, tiempo y circunstancia determinados y de las fuerzas objetivas que los determinan. ¿Es que no hay siempre elementos objetivos que envuelven de antemano las relaciones entre los sujetos, que se adelantan a ellas y las definen, dotándolas además de un significado que trasciende a las conciencias - y éstas acogen-, ya se trate del pasado común, de la cultura que comparten, o de otros aspectos objetivos que pueden aportar cada uno de ellos a su relación con el otro? Si es así, hemos de concluir que la noción de la intersubjetividad, así presentada como un modo de ser trascendental de la conciencia y abstraída, por lo tanto, de su concreta forma social y de su determinación natural, es una ficción del idealismo filosófico. Y que la pretensión misma de analizar la intersubjetividad en esos términos, que es justamente la tarea que emprende y desarrolla Husserl en la quinta meditación cartesiana, delata el carácter abstracto-especulativo de su análisis. Ahora bien, este concepto sí tiene sentido y es coherente con el conjunto del pensamiento de Husserl, en cuanto admite la noción de un sujeto puro, ante el cual y como parte de su mundo comparecen los otros con su propia subjetividad: el ego puro es para él el verdadero yo de la conciencia. Es verdad que Husserl puede reconocer que sólo a través del otro me conozco como hombre, y que en ese sentido mi ser mundano se define a partir de mi relación con los demás. Pero, como siempre en Husserl, ocurre que el sentido de esa realidad mía constituida en la relación interhumana ha de poder ser remitido en última instancia al plano originario de constitución de todo sentido, que es el del ego monádico. De nue- 
vo aquí se renueva esa paradoja de un yo que, siendo mundano, es al mismo tiempo -en cuanto sujeto trascendental- condición del mundo en el que está.

El planteamiento de Husserl está condicionado por su toma de posición inicial, de cuño cartesiano, lo cual le lleva a plantear la discusión en los términos de un cierto subjetivismo, a saber: ¿cómo se me aparece el yo de los otros? Sin embargo, no la aborda al modo en que lo hace el idealismo subjetivista moderno, es decir, no pretende "deducir" la realidad de los otros hombres con su mundo interior de vivencias a partir de las representaciones de mi conciencia. Más bien lo discute según el enfoque característico de la fenomenología: se trata de reducir la experiencia del yo extraño al sentido que en absoluto puede tener esa experiencia para mí, la cual necesariamente me remite en última instancia a mi yo singular. Es verdad, sin embargo, que de hecho siempre me encuentro entre otros que tienen sus propias experiencias y cuya conciencia centraliza sus particulares vivencias, entre las cuales debo admitir también la que se refiere a mí en cuanto me convierto en objeto de su consideración. $i^{84}$. Del mismo modo que los demás son parte de una vida - la mía- que se entiende a sí misma organizada en torno a mi conciencia como centro, mi propio yo se me aparece también descentrado, en cuanto formo parte de las vivencias de otros centros de experiencia que me son ajenos. Por lo tanto, la experiencia del alter ego replantea de una manera nueva y más profunda la cuestión de la alteridad y su posible reducción a la mismidad de mi conciencia, pues ya no se trata sólo de la constatación de que hay otros yoes, sino que además lo Otro en general del mundo se me revela ahora como objeto de una conciencia ajena e interpretado por ella: como lo Otro del otro. A este respecto, Husserl afronta este problema del descentramiento hacia el que parece deslizarse el yo cuando se concibe como parte de la vivencia ajena mediante la reducción fenomenológica de esa experiencia, de modo que la vivencia que el otro tiene de mí es, a su vez, integrada entre mis propias vivencias. A esto precisamente se refiere Husserl cuando habla de "la doble reducción fenomenológica" en las Lecciones de 191011, conocidas como Problemas fundamentales de la fenomenología ${ }^{85}$.

\footnotetext{
${ }^{84}$ Por eso dirá Sartre, prosiguiendo con esta reflexión, que la aparición del prójimo significa un descentramiento del mundo que al mismo tiempo socava la centralización operada por mí. Vid. El ser y la nada, Madrid, Alianza Universidad / Losada, 1984, p. 284. Traducción de Juan Valmar.

${ }_{85}$ Vid. Edmund Husserl, Problemas fundamentales de la fenomenología, § 39, pp. 124ss.
} 
Por otro lado, esta conexión entre la experiencia de los diversos sujetos ha de admitirse si queremos dar cuenta del significado de la objetividad del conocimiento, cuya validez universal implica el reconocimiento de su valor intersubjetivo. En efecto, el recurso al prójimo es condición indispensable para la constitución de un mundo común, el cual se me revela en el conocimiento racional y científico. Como comenta Hyppolite, esta cuestión no ocupa un primer plano entre los filósofos clásicos anteriores a Kant, porque el cogito conduce primero a Dios como garantía suprema de la objetividad. Pero cuando el pensamiento crítico rechaza ese salto ontológico, el problema de la constitución de la experiencia viene a tropezar necesariamente con la cuestión del otro ${ }^{86}$. La universalidad de la razón, que funda la ciencia, así como la pretensión de universalidad de los valores morales, tiene por lo tanto este significado antropológico de poner de manifiesto una vía a través de la cual el sujeto trasciende su particularidad como individuo, superando en este punto al menos el solipsismo, que es la tentación de una filosofía que concibe al sujeto trascendental en su máxima concreción como un yo monádico aislado.

En general, nos parece que en la discusión del problema de la intersubjetividad Husserl combina dos enfoques. Por un lado, desde una perspectiva subjetivista de cuño cartesiano, se trata de saber cómo a partir de mí mismo se me hace presente la subjetividad del otro, es decir, cómo se genera la esfera intersubjetiva (a partir de la cual podríamos entender entonces el fundamento del mundo objetivo). Pero, por otro lado, se nos plantea como problema el hecho insoslayable de que el mundo en que me desenvuelvo lo reconozco, en buena medida, como un mundo común y compartido con los demás, de tal manera que en este segundo enfoque la relación intersubjetiva estaría presupuesta (y ello exigiría entonces encontrar en la conciencia la base de la misma). Pero, en realidad, esos dos enfoques son complementarios y expresan el doble sentido de la intencionalidad: el que va de la conciencia al objeto y el que, a partir de éste, busca en la conciencia las operaciones que lo constituyen. Dicho de otro modo, la realidad de un mundo intersubjetivo es el nóema que sirve de hilo conductor trascendental para hallar en la conciencia las funciones noéticas que lo configuran; y, a la inversa, desde el yo monádico, y siguiendo el despliegue

${ }^{86}$ Jean Hyppolite, "L'intersubjectivité chez Husserl", en Écrits de Jean Hyppolite, I, Paris, P. U. F., 1971 , p. 504. 
de su intencionalidad constituyente, se trata de aprehender analógicamente la experiencia del extraño y, más allá, la de una realidad que él comparte conmigo.

Pues bien, Husserl indica que esa experiencia compartida apunta a una "esfera del ser trascendental como intersubjetividad monadológica"87; es decir, el ego trascendental es una conciencia intersubjetiva. Por lo tanto, Husserl reconoce a la intersubjetividad de la conciencia un papel constituyente del sentido de los fenómenos sociales y del mundo objetivo en general. De igual modo que la subjetividad es temporal y encarnada en un cuerpo, también es intersubjetiva, y la reducción fenomenológica descubre que el mundo es, en cuanto fenómeno, el resultado de la actividad constituyente de la intersubjetividad trascendental ${ }^{88}$, lo cual nos obliga a atribuir un carácter fundante a esa conciencia intersubjetiva.

En términos generales, nos parece que el término "intersubjetividad" es utilizado de manera equívoca por Husserl, y ello por diversas razones:

a) En primer lugar, porque - como hemos dicho- a veces tiende a confundirse con el mundo objetivo, en tanto que compartido, del cual decimos entonces que es intersubjetivo. Pero ese uso del término obedece - según se ha señalado- al subjetivismo que alienta en el pensamiento de Husserl, en el cual el objeto es reducido una y otra vez al sujeto.

b) Por otro lado, y en otro sentido, se plantea otra ambigüedad cuando el término en cuestión se refiere tanto a las relaciones entre diversos sujetos, de las cuales decimos entonces que son intersubjetivas, como también a un modo de ser trascendental de la conciencia, en cuyo caso decimos que ésta es intersubjetiva. Así, por ejemplo, habla Husserl de una "comunidad intermonádica"89 y de "intersubjetividad monadológica"90. En este caso, la ambigüedad también es calculada, porque de acuerdo con su interpretación esas relaciones intersubjetivas en las que el yo siempre se encuentra inmerso han de poder ser reducidas al yo monádico, de modo que el alter ego tiene que comprenderse como una ampliación al otro del ego singular, cuya conciencia sería entonces intersubjetiva.

\footnotetext{
${ }^{87}$ Meditaciones cartesianas, Meditación quinta: "Descubrimiento de la esfera del ser trascendental como intersubjetividad monadológica", pp. 119ss.

${ }^{88}$ Vid. Javier San Martín, La fenomenología de Husserl como utopía de la razón, p. 117.

${ }^{89}$ Meditaciones cartesianas, Meditación quinta, §§ 55-56, pp. 159ss.

${ }^{90}$ Esta expresión forma parte del título de la meditación quinta.
} 
c) En tercer lugar, el concepto de intersubjetividad es referido al conocimiento de distintas regiones del ser, de modo que Husserl puede decir ya en las Lecciones de 1910-11 que "intersubjetivo es todo conocimiento matemático"91, y que "es intersubjetivo, igualmente, cualquier conocimiento físico"92. A lo cual podríamos añadir que también es intersubjetivo el conocimiento de los "objetos" culturales, los cuales, a diferencia de los objetos matemáticos -que son ideales- y de los objetos físicos - que son reales, con una realidad independiente de la realidad humana-, son constructos que obedecen a la acción humana concertada, aunque Ileguen a tener una inercia propia u objetiva. Así pues, la intersubjetividad del conocimiento en algún caso, como el de la lógica o las matemáticas, no requiere de ningún intercambio de experiencias. Por el contrario, la intersubjetividad del conocimiento empírico requiere del intercambio de experiencias entre los sujetos. Este intercambio puede construir un mundo común con significados objetivos, como los que constituyen la esfera social y cultural.

En cualquier caso, según Husserl, el reconocimiento compartido de una misma realidad objetiva (el ser de la naturaleza o el de la cultura) que se impone a los sujetos individuales entraña alguna forma de intersubjetividad en la que se encuentra el significado del objeto en cuestión. Ahora bien, ese significado tiene que poder ser comprendido como una modificación intencional de un sentido primigenio constituido para dicho objeto en la esfera de la plena concreción monádica del yo ${ }^{93}$. La constatación de que hay un mundo común compartido y otros centros de experiencia distintos del mío plantea al fenomenólogo la tarea de encontrar en la conciencia del yo monádico el sentido último de esa experiencia. Por eso, Husserl recurre a la reducción fenomenológica para explicar "la aparición del otro yo":

91 "Cualquiera provisto de intuición espacial [podría] emitir y ejecutar los mismos juicios acerca del espacio con los mismos fundamentos[...]". Ese conocimiento - añade- se refiere a la esencia ideal de algo general, que es no sólo independiente de los actos singulares llevados fácticamente a cabo para alcanzarlo, sino que además, aun siendo intersubjetivo, no requiere de intercambio alguno de experiencias. Vid. Problemas fundamentales de la fenomenología, Anexo XXV al § 36, pp. 177s.

92 Aunque, en este caso, por otra razón - según aclara Husserl-: "por lo que respecta al conocimiento físico, su intersubjetividad radica en que todos podemos mirar uno y el mismo mundo espaciotemporal al que, por nuestro cuerpo, pertenecemos nosotros mismos [...]" Aquí se trata, por lo tanto de un conocimiento empírico, respecto del cual - añade a continuación- "los diferentes individuos, gracias al «intercambio» de sus conocimientos y relaciones de conocimiento, pueden constituir un sistema de coordenadas común [...] y un punto temporal que sea en cierto modo determinable de forma común". De tal manera que "cada conocimiento experiencial intersubjetivo está relacionado con un grupo [...] de seres inteligentes que están en relación de posible empatía". Idem.

${ }_{93}$ Meditaciones cartesianas, Meditación quinta, §§ 44-48, pp. 125ss. 
Tenemos que procurarnos una visión que penetre en la intencionalidad explícita e implícita en la que, sobre la base de nuestro ego trascendental, el alter ego se anuncia y verifica: tenemos que ver cómo, en qué intencionalidades, en qué síntesis, en qué motivaciones se configura en mí el sentido alter ego [...] Esta experiencia y sus efectuaciones son $[\ldots]$ hechos trascendentales de mi esfera fenomenológica. ${ }^{94}$

Así pues, una vez establecido el significado trascendental de la intersubjetividad en relación con la noción de un mundo común compartido, Husserl pretende a su vez reducir la esfera intersubjetiva a la esfera propia del yo monádico, de tal manera que la intersubjetividad es comprendida a través de una "ampliación" al otro de la propia subjetividad, que mediante una doble reducción remite primero la experiencia ajena al yo-otro que la constituye y, segundo, retrotrae esa experiencia a mi propia subjetividad, tan sólo en la cual según Husserl- se origina todo sentido. Pero ¿cómo salgo de mí mismo hacia los otros? En realidad, así planteada, esta pregunta presupone algo falso, porque el yo nunca ha estado encapsulado en sí mismo como si se tratara de una mónada originalmente aislada. En este punto fue más lúcida la posición de Hegel, desarrollada por Marx y, a su manera, también por Freud: el yo monádico es una ficción $y$, en consecuencia, no hay tal salida de mi yo hacia los otros yoes, puesto que sólo entre los otros y frente a ellos se constituye el sí-mismo singular que soy. En otros términos: mi autoconciencia contiene como uno de sus momentos esenciales el del yo-otro, y lo contiene como un momento cooriginario de su propia constitución. De tal manera que, como nos explicó Hegel en el célebre pasaje de la Fenomenología del espíritu acerca de la lucha por el reconocimiento, una autoconciencia sólo es posible junto y frente a otra, y nunca aisladamente. Dicho de otra manera: no hay un yo monádico primigenio, cuya mismidad sea previa al ser de los otros, porque el yo se constituye precisamente como un yo-otro respecto de los otros. Sin embargo, el pensamiento de Husserl permanece fiel a una filosofía del cogito, de modo que la intersubjetividad será subordinada al ego meditans. Como comenta Hyppolite, éste es el punto principal donde el planteamiento de Husserl difiere del de Hegel, quien reconoce este problema en la Fenomenología del espíritu. Pero para Hegel se trata siempre de la constitución del nosotros, de tal manera que para él la formación de la intersubjetividad trasciende cada una de las conciencias de sí en

\footnotetext{
94 Ibidem, Meditación quinta, § 42, pp. 121s.
} 
las que aquélla se constituye. Husserl, por el contrario, no se sitúa en el marco de una filosofía del espíritu, sino en el de una filosofía del cogito ${ }^{95}$. Por lo tanto, desde su punto de vista, aun cuando la subjetividad del hombre vive en un horizonte social, ocupado por cuerpos y de carácter temporal, la condición de sentido de esas realidades radica en el yo que se adelanta a mi cuerpo y a los otros, y cuyos recuerdos y proyectos distienden el ahora fluyente de la conciencia hacia el pasado y el futuro. Así pues, de acuerdo con el enfoque de Husserl, los sentidos compartidos intersubjetivamente (por ejemplo, los que se hallan en los símbolos culturales) han de poder ser retrotraídos ellos mismos a su vez al momento primordial de constitución de todo sentido en la esfera del yo propio.

Por lo tanto, la invocación de un yo monádico puro le permite a Husserl reducir la intersubjetividad a la esfera de la propia mismidad. Por eso dice Szilasi, interpretando a Husserl, que yo estoy presente a mí mismo como yo puro, pero mi determinación psicofísica (o sea, el yo psicofísico que soy con todo mi mundo vital, en el que encuentro también a los otros) me está co-presentada. A partir de ahí, Husserl considera legítima la tarea de determinar la esfera propia y exclusiva de mi yo individual a través de una epoché que lleve a cabo la reducción de la experiencia trascendental a la esfera de la pura mismidad del ego monádico: hacemos abstracción de todo lo mundanal constituido intersubjetivamente para alcanzar el "sí-mismo propio" y, como su correlato, lo que es exclusivamente suyo en su experiencia del mundo ${ }^{96}$.

Así pues, se trata ahora del yo trascendental en su máxima concreción, tan sólo a partir del cual aparecen todos los sentidos, incluido el del mundo como tal con los sujetos que lo habitan. Pero llevar a cabo semejante empresa significa determinar con precisión "la esfera de lo que me es propio" (Eigenheitssphäre) como concreto yo monádico, haciendo abstracción de toda intencionalidad referida a la subjetividad extraña para alcanzar así el ámbito de la mismidad en que se constituye "lo propio de mi ego" ${ }^{\prime \prime 7}$. La pretensión de realizar esta separación delata - aparte de lo que ya se ha comentado antes- el significado antidialéctico del enfoque de Husserl, porque supone la tesis de que es posible aislar el yo individual y definir en él un estrato último en que se constituye originariamente el sentido de lo real. Aun aceptando que el sentido de un mundo

\footnotetext{
95 Jean Hyppolite, op. cit., pp. 506s.

${ }^{96}$ Meditaciones cartesianas, Meditación quinta, § 44, pp. 129-131.

97 Ibidem, Meditación quinta, § 44, pp. 125ss.
} 
común remite a la pluralidad de los sujetos que lo experimentan y contribuyen a configurarlo, su reducción a la esfera trascendental de mi conciencia reconduce aquel sentido a mi ego monádico como estrato último en el que se instituye, pues:

La reducción trascendental me liga a la corriente de mis puras vivencias de conciencia. [...] [Éstas] son inseparables de mi ego y [...] pertenecen a la concreción misma del ego. [...] Pero, ¿qué sucede entonces con los otros egos? ${ }^{98}$

La apelación en este contexto a la analogía pone de manifiesto la dificultad de esa tarea. En las anteriormente ya citadas Lecciones del semestre de invierno de 1910-11, conocidas y publicadas como Problemas fundamentales de la fenomenología, no sólo recurre Husserl a la analogía, sino también al concepto de "empatía" (Einfühlung), que significa una especie de proyección que nos abre a la vida anímica del otro ${ }^{99}$. De acuerdo con el enfoque de estas Lecciones, a través de la empatía una conciencia tendría la vivencia de otra conciencia distinta ${ }^{100}$, operando además aquí un tipo especial de analogía: en ella no se alcanza la representación del otro en una imagen, sino que intuimos en el otro su vivencia de manera inmediata y no al modo en que lo hace la conciencia representativa y objetivadora. Es decir: no se trata de la "representación" del otro en una imagen de la fantasía (Verbildlichung) y en analogía con la representación que pueda tener de mí mismo, sino de su "presentización" (Vergegenwärtigung $)^{101}$, en la que se me revela su intimidad.

En las Meditaciones cartesianas apenas aparece el término "empatía", quizá por las resonancias irracionales que suscita ${ }^{102}$; en cambio, sí encontramos aquel uso sui generis de la analogía, noción que se emplea en conexión con la experiencia del cuerpo ajeno. A este respecto, Husserl distingue entre el "cuer-

98 Ibidem, Meditación quinta, § 42, p. 120.

${ }_{99}$ Problemas fundamentales de la fenomenología, passim.

${ }^{100}$ Ibidem, § 38, pp. 122s.

101 Ibidem, \$ 38, pp. 123s. La decisión del traductor de transcribir este término como "representificación" es discutible, y quizá fuera preferible "presentización" o incluso "apresentación", ya que este último término -que luego será utilizado en las Meditaciones cartesianas- aparece cuando más adelante en estas mismas Lecciones dice Husserl que la intimidad del otro no se me hace presente directamente, sino que sólo se hace "apresente" (appräsent) a través de su cuerpo, en cuanto éste remite a un yo. Este yo es "compresente" con relación a su propio cuerpo, y se hace "apresente" en la esfera de mi propia experiencia. Por cierto que Ortega recoge este mismo enfoque en El hombre y la gente, cap. IV.

102 El término en cuestión aparece de pasada en el § 43, p. 123 de la edición citada, pero Husserl lo menciona una vez, distanciándose de él y sin asumirlo claramente. Parece que Husserl tomó inicialmente este concepto de Theodor Lipps - aunque no su teoría sobre el tema-, pero no le satisfizo nunca del todo y acabó por dejarlo más bien de lado. Vid. el comentario al respecto de Mario A. Presas en la nota 38 de su traducción de las Meditaciones cartesianas, pp. 123s. El profesor Roberto Walton piensa, sin embargo, que Husserl siempre sostuvo vigente ese concepto (observación expresada en una conversación particular). 
po físico" (Körper), que es el cuerpo considerado como cosa u objeto espacial, y el "cuerpo orgánico" (Leib), que es el cuerpo vivido como organismo propio. De tal manera que cada yo en principio experimenta al otro como cuerpo físico, y a sí mismo como cuerpo orgánico; pero también se experimenta a sí como cuerpo físico en cuanto puede adoptar una actitud enajenante hacia su propia corporeidad $^{103}$. Pero habla también del "cuerpo físico-orgánico" (Leib-Körper) ${ }^{104}$ cuando considera el cuerpo del otro que, aunque primariamente para mí es cuerpo físico, también lo experimento en analogía con la vivencia de mi propio cuerpo, que siendo físico se me presenta como cuerpo orgánico ${ }^{105}$ : experimento a los otros como yoes que gobiernan psíquicamente en sus propios cuerpos. $Y$ este es el camino de acceso a las vivencias del otro yo, pues:

sólo una similitud que, dentro de mi esfera primordial, enlace aquel cuerpo físico con mi cuerpo físico puede ofrecer el fundamento de motivación para la aprehensión analogizante del primero como otro cuerpo orgánico. ${ }^{106}$

Esta "aprehensión analogizante" —nos dice a continuación- es una especie de "apercepción asimilante" y no una inferencia por analogía: una apercepción en la que comprendemos un sentido en cuanto lo remitimos intencionalmente a una "instauración originaria" en la cual se había constituido por primera vez un objeto de similar sentido. De tal modo que, según Husserl, la aprehensión del sentido del alter ego a partir de mi propio ego, y, en general, la comprensión de cualquier sentido de la experiencia cotidiana, sólo se produce mediante esa "transferencia analogizante" de un sentido objetivo, ya originariamente instaurado, al nuevo caso ${ }^{107}$. Es ésta una explicación del proceso de la experiencia en la que los nuevos sentidos objetivos se aclaran retrotrayéndolos a las apercepciones correspondientes en las que se encuentra un sentido semejante al que se asimila el nuevo, y, en definitiva, finalmente a la esfera de la plena concreción del yo monádico, como condición de posibilidad de todo sentido.

\footnotetext{
${ }^{103}$ Esto último ocurre, por ejemplo, cuando uno se distancia de su propia mano y la mira al modo en que lo haría un observador que decide dibujar un objeto, o cuando nos miramos en un espejo. La técnica de los trasplantes de órganos, tan extendida hoy, nos permite también pasar de un concepto a otro, colocándonos en el lugar de quien se ha sometido a un trasplante y convierte el cuerpo físico que en principio le es extraño (el órgano que se le trasplanta) en parte de su cuerpo orgánico.

104 Sobre estos significados y las traducciones propuestas, sigo las sugerencias de Mario A. Presas en la nota 9 de la página 26 de su traducción de las Meditaciones cartesianas.

105 Ibidem, Meditación quinta, § 43, pp. 122s.

106 Ibidem, Meditación quinta, § 50, p. 147.

107 Idem.
} 
sí pues, el otro se "apresenta" en virtud de esa analogía que nunca alcanza a captar la conciencia ajena como algo presente en una percepción, sino - dice Husserl evitando el término "empatía" - en una "aprehensión analogizante": el extraño sólo es concebible como analogon de mi mismidad y con un sentido que necesariamente sólo se constituye como modificación intencional de mi yo objetivado. Por lo tanto, "desde el punto de vista fenomenológico, el otro es una modificación de mí mismo" ${ }^{108}$.Y pocas líneas después añade:[el ego extraño lo experimento como] "un yo apresentado que no soy yo mismo, sino que es mi modificatum: «otro yo»"109. En rigor, el yo $-\mathrm{y}$ cualquier yo- se aparece en una apercepción, aunque se trate del yo ajeno: "Mi ego primordial constituye el ego que es otro para él en virtud de una apercepción apresentativa" ${ }^{110}$.

Se hace claro, por lo tanto, que para Husserl el otro yo es siempre derivado respecto del ego primordial, identificado con el yo monádico propio, de tal manera que para él -como dice Wilhelm Szilasi- el único acceso posible al otro es la explicitación de lo mío propio ${ }^{111}$. De este modo, pues, Husserl se aparta decididamente de aquella otra tradición del pensamiento que, desde Hegel, considera la alteridad tan originaria como la mismidad, hasta el punto de poder afirmar - frente a Husserl- que la constitución de la mismidad del yo es inseparable del proceso por el que ese yo deviene el otro del otro, de manera que finalmente la verdad del yo es el nosotros.

Por otra parte, el recurso en este contexto a la "apercepción analogizante" para aprehender la conciencia del otro es una aplicación en el terreno de la intersubjetividad del concepto "trascendencia en la inmanencia", mediante el cual trata de "reducir" lo trascendente a la conciencia relativizando su oposición con lo inmanente, al tiempo que retrotrae la objetividad de las cosas a la constitución de su sentido en la conciencia. El problema con Husserl es siempre el de esta "constitución de lo Otro", que no consiste en crear o dar realidad a partir del ego, pero sí en otorgar sentido a cualquier realidad que se me presenta. Siempre nos topamos con ese procedimiento en virtud del cual lo extraño se reencuentra como reconstruido por el yo. En éste siempre se presume un sentido ya comprendido, tan sólo a partir del cual y por asimilación al mismo - por

\footnotetext{
108 Ibidem, Meditación quinta, § 51, p. 152.

${ }^{109}$ Ibidem, p. 153.

${ }^{110}$ Ibidem, Meditación quinta, § 54, p. 157.

111 Wilhelm Szilasi, op. cit., p. 132.
} 
aprehensión analogizante- puede comprender otros sentidos que se le propongan. $Y$ así procede el conocimiento: atribuyendo al objeto que se me presenta un sentido ya conocido en otros objetos, que ahora reconozco -aunque sea a través de una analogía asimilante- en el nuevo. La necesidad de esa conexión de lo extraño con lo ya conocido, para que aquello pueda ser asimilado -que Husserl expresa mediante el término "apareamiento" o "parificación" (Paarung ${ }^{112}$ ) - se produce de tal manera que lo extraño sólo resulta accesible mediante la modificación intencional de mí mismo.

Pero la pretensión de llevar a cabo esta última reducción revela de por sí, a su vez, un supuesto fundamental del pensamiento de Husserl: que no hay sentidos que se impongan al yo sino sólo en cuanto éste los interpreta desde su mismidad monádica. Y ello delata, a su vez, una cierta posición respecto de la dinámica cultural que se nos antoja difícil de mantener ante el testimonio abrumador de las ciencias sociales, que tozudamente indican -en contra de la asignación de un papel primario a la iniciativa individual por parte de Husserlque la forma que adopta la conciencia del individuo es un producto social y que la subjetividad es un resultado derivado de la dinámica cultural que modela a los individuos, los cuales a lo sumo se apropian de los sentidos que les sobrepasan para interpretarlos desde su singular posición elaborando de paso el espacio de su propia subjetividad. Ahora bien, el problema radica en determinar con precisión qué quiere decir "reducción" en este punto concreto. Porque Husserl admitiría sin problemas que los símbolos culturales no son establecidos por el yo, sino que lo trascienden necesariamente. Pero añadiría que la cuestión estriba en saber qué significan esos símbolos para mí, puesto que sin un sujeto que salga intencionalmente a su encuentro para apropiárselos nada serían en realidad. Ahora bien, eso quiere decir que la fenomenología desatiende a la dinámica independiente de la vida social y que se encuentra con la dificultad de dar cuenta de los procesos de cambio y de diferenciación cultural. Pues si todo sentido se origina en la conciencia - que no se limitaría, por tanto, a acoger lo que se le impone-, ¿cómo dar cuenta del sentido de los procesos sociales objetivos? Pero es que, además, esa apelación a lo que sean esos símbolos para mí,

112 El significado de este término alude a esa conexión, pero tiene además una connotación biológica que indica metafóricamente que esa "unión" (de lo extraño con lo ya conocido) es precisamente lo que "hace nacer" el nuevo conocimiento. Sin embargo, la parificación tiene un significado más general en el pensamiento de Husserl, porque se trata de una forma originaria de asociación en la síntesis pasiva. 
en tanto yo me los apropio, no salva el carácter primario de esa apropiación como si fuera una actividad originaria del sujeto, pues esa apropiación que los individuos hacemos de los significados que nos sobrepasan está a su vez regida por pautas sociales de las que a menudo el propio yo individual ni siquiera es consciente.

Por eso nos parece que su filosofía, en la tradición del idealismo moderno, lleva a cabo una hipóstasis del yo, aislando y considerando separadamente el momento de la subjetividad que necesariamente acompaña a toda experiencia que pueda llamarse en verdad humana. Ese momento subjetivo tiene lugar ciertamente en cuanto el individuo no sólo acoge sino que se apropia desde sí mismo del sentido de las cosas, que le es siempre ya dado de antemano como una realidad objetiva que se le impone y que él, a su vez, interpreta desde su singular posición contribuyendo a recrearla. Pero esa apropiación o interpretación está también subordinada a factores objetivos. Pues bien, Husserl desenraíza y abstrae ese momento subjetivo, destacando además su papel activo -en la línea del idealismo que privilegia la relación de conocimiento- e interpretándolo de acuerdo con su doctrina de la intencionalidad constituyente. De ese modo distingue del yo mundano un yo que se adelanta al mundo en cuanto condición de posibilidad de éste. Pero la originalidad y la sutileza de su planteamiento, y al mismo tiempo lo que hace tan difícil su comprensión -sobre todo si tratamos de asimilarlo al de Kant-, estriba en la concepción de ese ego puro - que se tiene inmediatamente a sí mismo como tal- como el que igualmente se determina como el yo psicofísico con su mundo vital (el yo mundano), en el cual -y como parte del mismo- se encuentran los otros yoes, con los que comparte además un mundo común. El primado del ego puro, en cuanto ego trascendental, se refiere entonces a su comprensión como esfera originaria de donación del sentido. 